\title{
Neoliberal digitality, labour and leisure in an MMOG: An ethnography and analysis
}

\section{By}

\section{Tamara Paradis}

A thesis submitted to the department of Sociology and Anthropology in partial fulfillment of the requirements for the degree of

Master of Arts

to

The Faculty of Graduate Studies and Research

Department of Sociology and Anthropology

Carleton University

Ottawa, Canada

January, 2010

(C) 2010, Tamara Paradis 


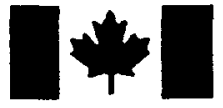

Library and Archives

Canada

Published Heritage

Branch

395 Wellington Street

Ottawa ON K1A ON4

Canada
Bibliotheque et

Archives Canada

Direction du

Patrimoine de l'édition

395 , rue Wellington

Ottawa ON K1A ON4

Canada
Your file Votre référence

ISBN: 978-0-494-68695-9

Our file Notre référence

ISBN: 978-0-494-68695-9
NOTICE:

The author has granted a nonexclusive license allowing Library and Archives Canada to reproduce, publish, archive, preserve, conserve, communicate to the public by telecommunication or on the Internet, loan, distribute and sell theses worldwide, for commercial or noncommercial purposes, in microform, paper, electronic and/or any other formats.

The author retains copyright ownership and moral rights in this thesis. Neither the thesis nor substantial extracts from it may be printed or otherwise reproduced without the author's permission.
AVIS:

L'auteur a accordé une licence non exclusive permettant à la Bibliothèque et Archives Canada de reproduire, publier, archiver, sauvegarder, conserver, transmettre au public par télécommunication ou par l'Internet, prêter, distribuer et vendre des thèses partout dans le monde, à des fins commerciales ou autres, sur support microforme, papier, électronique et/ou autres formats.

L'auteur conserve la propriété du droit d'auteur et des droits moraux qui protège cette thèse. $\mathrm{Ni}$ la thèse ni des extraits substantiels de celle-ci ne doivent être imprimés ou autrement reproduits sans son autorisation.
In compliance with the Canadian Privacy Act some supporting forms may have been removed from this thesis.

While these forms may be included in the document page count, their removal does not represent any loss of content from the thesis.
Conformément à la loi canadienne sur la protection de la vie privée, quelques formulaires secondaires ont été enlevés de cette thèse.

Bien que ces formulaires aient inclus dans la pagination, il n'y aura aucun contenu manquant. 


\section{CARLETON UNIVERSITY}

\section{FACULTY OF GRADUATE STUDIES}

The undersigned certify that they have read, and recommend to the Faculty of Graduate Studies for acceptance, a thesis entitled "Neoliberal digitality, labour and leisure in an MMOG: An ethnography and analysis" submitted by Tamara Paradis in partial fulfillment of the requirements for the degree of MASTER OFARTS.

Supervisor

Dr. Justin Paulson

Department of Sociology and

Anthropology

Internal Examiner

Dr. Justin Paulson

Department of Sociology and

Anthropology

External Examiner

Dr. Jennifer Jenson

Associate Professor

York University 


\begin{abstract}
How does the massively-multiplayer online gameworld (MMOG) of World of Warcraft (WoW) refute or reflect the capitalist leanings of the neoliberal culture in which it is situated? How does this understanding of gaming as suspect leisure feed out into the everyday understood associations between gaming, leisure, labour, and being in a neoliberal context? Using these questions as a foundation for investigation, this thesis analyzes connections between gameworld participation as an activity, the WoW gameworld as a lived environment, and that activity and gameworld's relation to leisure, labour and being, and demonstrates how these understandings commit at least one of four ontological errors. By situating gameworld participation as a set of hybrid work-leisure practices that re-inscribes neoliberalism, this thesis will describe how MMOG participation is an activity that is a full corroboration of the work, consumption and action orientations of western neoliberal capitalism.
\end{abstract}




\section{Acknowledgements}

To Dr. Justin Paulson and the entire sociology department at Carleton University, for supporting my vision and guiding my path.

To the Social Sciences and Humanities Research Council, for providing the financial support that enabled my ethnography. My gratitude.

To Dr. Bart Simon and the entire group of Concordia University's GameCODE research group: Thank you for showing me the possibilities for gameworld research within sociology.

To Kelly Boudreau: Thank you for setting an example for me, and for being my cheerleader, my editor and my stalwart friend.

To Lilly and Collin: Thank you for friendship and food, WoW knowledge and beer, raid groups and silliness.

To the fabulous and funny people in "Guild A": Thanks for letting me be a bad hunter, a mediocre mage and a covert observational rogue in your uber midst.

To Todd: For being there, despite not always being able to be there. I love you. Forever and always. 


\section{Table of Contents}

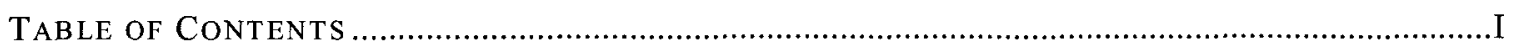

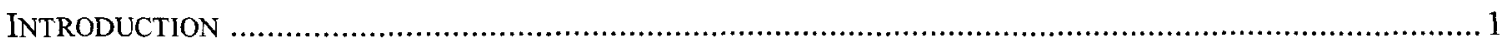

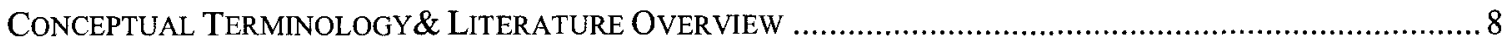

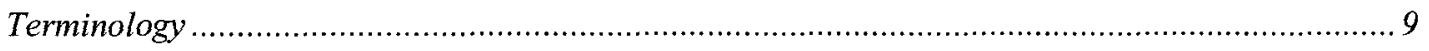

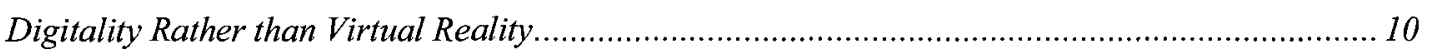

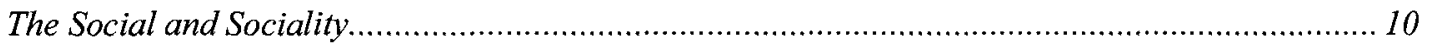

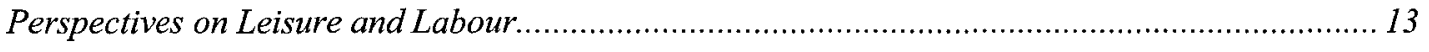

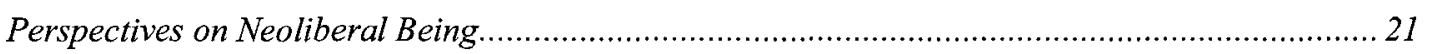

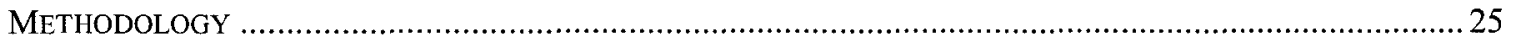

Intent

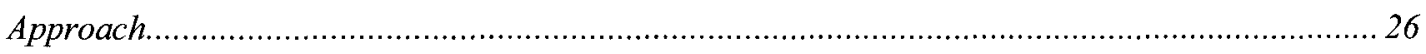

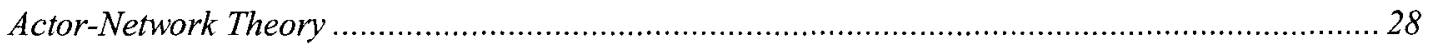

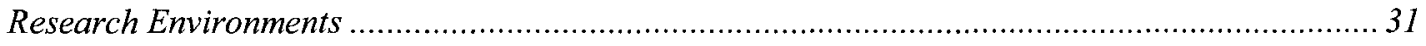

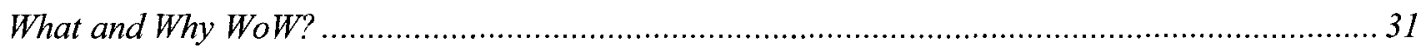

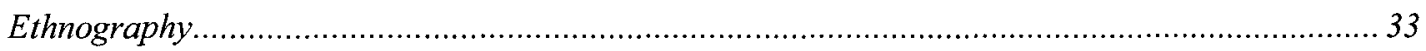

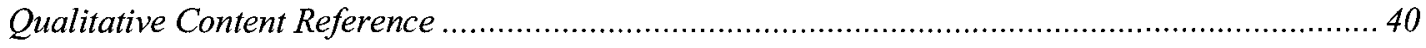

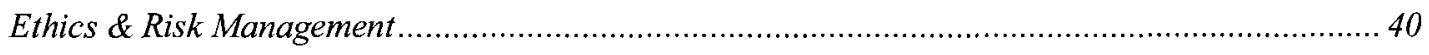

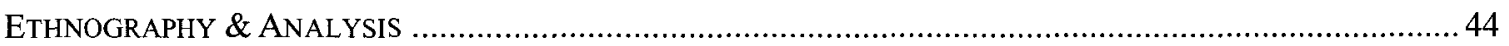

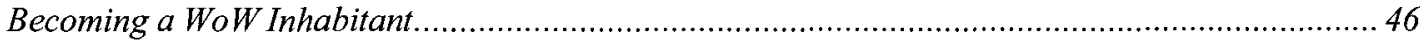

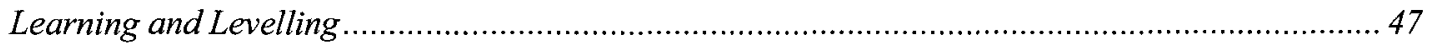

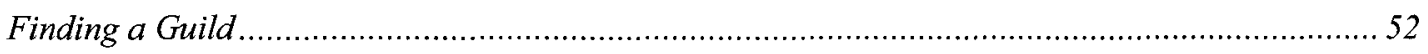

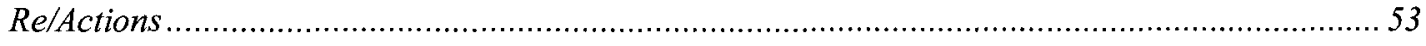

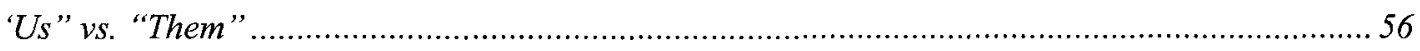

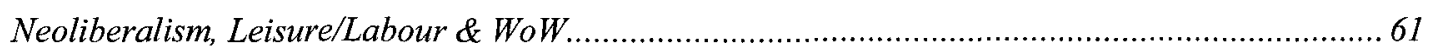

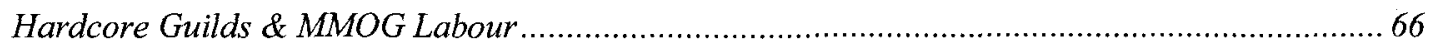




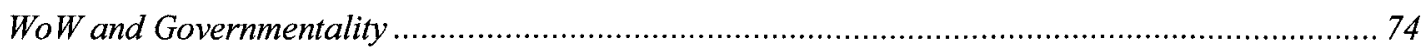

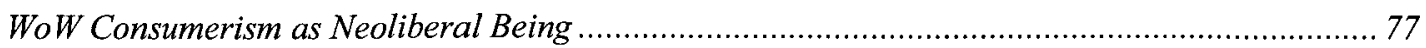

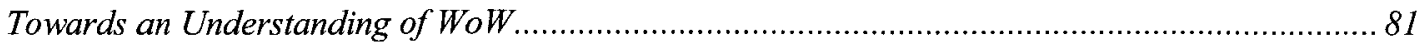

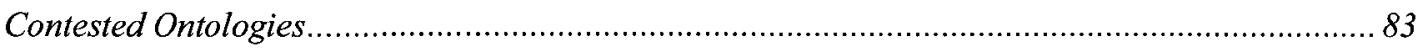

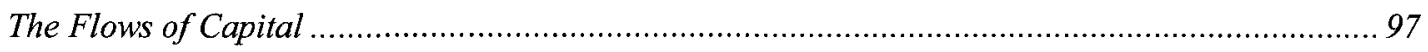

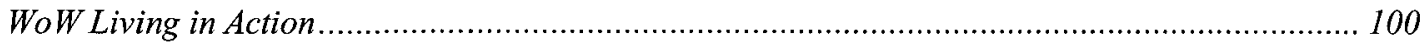

CONCLUSION

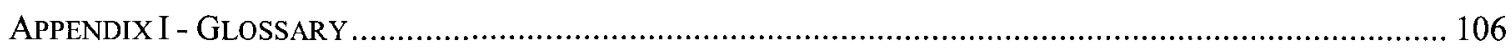

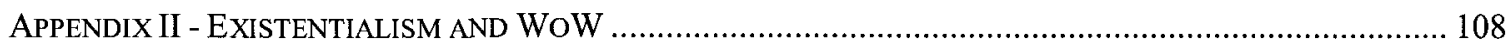

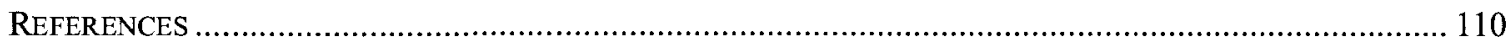




\section{Introduction}

"11 million people not having sex and never seeing the sun. Proud day for humanity."

Posted by a reader on Wired.com in response to Blizzard's announcements

of the new 2009 WoW subscriber figures

"I wonder, as I have in the past, why that singular image of the male teenage isolate hanging out and gaming online holds so strong in the face of real players."

(Taylor, 2006, p. 4)

"How many hours?"

“27!!"”

"Wow. WHOA. That would be awesome if it wasn't so lame."

"yeah I know, like get a life huh?"

"Yeah nk"

"Still cool though. Wonder how he did it?"

"It was a lock too. I totally thought it woulda been a paly. “

"Oh. Yeah. ... yeah! Palys suck. But palys > locks."

"Totally"

Caught up deeply in my own Wrath of the Lich King (WotLK) expansion frenzy, I nevertheless paused at this point and pondered this public city chat conversation. It was day three of the expansion, and I had been playing fairly constantly since the release on November 13 , 2008 at midnight here in Canada. I was trying to see how fast I, personally, could get my favourite level 70 character, a frost mage named Taryas, up to level 80 and whether I could be 
the first in my guild to do so. By the time this conversation happened in the general chat in the new zone of Borean Tundra, the fact that a French warlock named Nimh had reached the coveted pinnacle of level 80 first in the entire World of Worldcraft (WoW) universe was old but hot news. At this point, I was level 73, and while I was still ahead of anyone in my own guild in my levelling speed, I was constantly seeing various realm announcements pop up of other player's achievements in the game. Be it first to reach the maximum 450 level in a gathering profession (such as mining), first to conquer a specific boss in one of the new instance dungeons, or first to completely explore and discover every corner of every zone in the new areas, achievement was in the air and talk ran rampant. The mood in public conversations around these achievements vacillated between awe and eye-rolling. The awe was obvious and understandable, but the eyerolling was interesting to me, as both an academic and as a gamer who claims gaming as a primary leisure activity and social milieu.

The conversation example I have given was just one of a few hundred I saw in my own two week race to reach level 80 . Based on the chat on the blogosphere and on the official and unofficial game forums, the topic of how someone reached 80 so fast and what that said about his life and about gaming in general was a big focus. Understandably, the chat was not philosophical or even particularly analytical. As usually happens in such conversations, the opinions were primarily divided into two camps: those who though that Nimh was a loser who lived in his parents' basement and had no job, girlfriend or life outside the gameworld; and those who admired his achievement, recognized his choice to take a few days of vacation time from his job to do this and who thought it has to have been a lot of fun and very satisfying. 
The theme here then is split, between derision and admiration. The admiration tended to be straightforward, so it was the derision I found most interesting. Most often, the derisive talk ran to 'smacktalk', put downs or insults between various players around their relative skills and abilities (levelling speed being a big theme here) vis-a-vis others, characters' class characteristics ${ }^{1}$ or personal life attributes (the kind of bragging known as displaying one's 'epeen' or ego status). Along with the smacktalk was a lot of colour commentary, and much of it invoked hackneyed or hoary caricatures of gamers. Most often, people were drawing on the commonly understood stereotype of the pimple-faced anti-social gamer guy, who has no social skills, no friends, and no meaningful life in the 'real' world. Invoking this stereotype usually accompanied some commentary, serious or otherwise, of how the speaker differs from it. Sometimes the conversations were about how the gamer's girlfriend or wife or parent or boss was annoyed or angry with them for the amount of time they had been playing since WotLK's launch. Others would note that while they had played for anywhere from four to ten hours a day since launch, they had also gone to work, eaten dinner with family, paid bills, had sex, or done any myriad of other activities out of the gameworld.

What I see at work here is the unacknowledged operation of value judgements placed upon time and leisure. These reactions by the players themselves display an unreflexive adoption of the dominant values of western neoliberal society. This adoption of these neoliberal beliefs carries a value reflection about the waste of time that is engagement in online gaming. I do not claim that gamers are social dupes who are unable to distinguish the nuances between dominant

\footnotetext{
${ }^{1}$ A lot of the talk around classes and characters for the Wrath of the Lich King (WotLK) content expansion centred on the impacts of the new Death Knight class introduced and its possible impacts on Player vs Player (PvP), particularly within arena matches.
} 
social interpretations of gaming and their own practices. Nonetheless, it is difficult to argue against the idea that gamers do internalize and perpetuate these interpretations with often startlingly little reconfiguration of them. What is happening here?

In order to conceptualize the associations between online gaming and leisure and to start to tease out a framework which lays out more fully fledged questions to ask in future research, I will paint a confessional ethnographic picture of my gameworld emergence which I will use to interrogate the digitality that emerges and is sustained in these spaces. The ethnographic descriptions and detail from this emergence will lay the foundation for an analysis of what might be going on in the contested ontological space that surrounds the everyday understanding of online gameworld participation, enmeshed as it is in a web of associations both in and out of the gameworld of WoW. I will trace out some of the key intermediaries, mediators and assemblages that come into existence in the act of gameworld participation and the actions involved in sometimes living in a gameworld and reacting to those who do not. This is the point of this thesis.

I am attempting to unpack the ways in which gameworld participation as a form of leisure activity can be associated with an everyday sense of its suspicious character. Holding up those understandings to the light, I want to attempt to make them appear strange when compared against the dominant neoliberal context in which the associations circulate and I wish to demonstrate that far from being a space of difference, online gameworlds such as WoW are corroborating and shoring up the dominant neoliberal capitalist context within which they are embedded. Following Mol (1999), I am striving to tease out the threads of action that have created both the suspicious character understanding and the dominant neoliberal context that 
leads to those understandings. In doing so, I am formulating a picture of the ontological politics at work in the activity that is online gaming. I take the ontological politics concept from Mol, who describes it as follows:

Ontological politics is a composite term. It talks of ontology-which in standard philosophical parlance defines what belongs to the real, the conditions of possibility we live with. If the term 'ontology' is combined with that of 'politics', then this suggests that the conditions of possibility are not given. That reality does not precede the mundane practices in which we interact with it, but is rather shaped within these practices. So the term politics works to underline this active mode, this process of shaping, and the fact that its character is both open and contested (p. 75).

Given that what I have discovered is a clash of understandings between the two, my goal here is to trace out some of the associations between the two understandings of gaming as a reflection of neoliberal culture and gaming as a contested activity, in order to start to figure out what is happening in MMOG inhabitants' lives, including my own, as we negotiate the ontological issues that is the lived space of a gameworld.

There are no lines of causality that can be objectively determined and redrawn for analysis here. Given that I am using data and observations from an ethnographic field study in order to make my interpretations and analyses here, my work is inherently subjective and fluid. I agree with the approaches to ethnography of Van Maanen's (2004) Paccagnella's (1997) and Davies' (1999). As Davies argues, ethnography is suited to presenting an informed, reflexive and combined reality of a social environment, that is but one among many possible realities. The process of creating and presenting that reality comes from what Paccagnella calls "interpretive 
flexibility" (p. 2) and the very fact that it is a consciously constructed reality that puts the lie to causality. Thus, what I find and can offer are the fuzzy lines of association as seen in action, through the lens of my own gaming life, with its intersections in digitality and biological reality; but also the intersections and associations of these in the lives of others, gamers and non-gamers alike that became known to me during my fieldwork.

Following Mol, this ethnographic thesis is a construction story, a story of my discovery of these associations between gaming, leisure, labour and boundaries. Via my ethnography, my intent was to highlight the fact that other kinds of understandings of gaming as an activity and an ontology were possible and could still be actualized. "Constructivist stories suggest that alternative 'constructions of reality' might have been possible" (Mol, p. 76) in a "reality that is done and enacted rather than observed" (Mol, p. 77). Possible, yes, but not dominant. In this thesis then, I will show how the reality of gameworld participant's digitality is performed daily, via these associations, and how this package of performance and associations contribute to the contested political ontology that is gameworld digitality.

It is in these active and variable associations that we find any stuff that might be called social $^{2}$ and it is for these reason that this thesis is a piece of sociological work. For here, the social is the transient stuff of understandings on the perspective plane that is a gameworld inhabitant's digitality. It is here that traces of the social can be found in the circulation of associations between gaming, leisure and digitality. What I intend to show is how the social is a set of common understandings embedded within circulating processes of human life (Law, 2003). These understandings structure and shape everyday perceptions of good/bad, right/wrong

\footnotetext{
2 'Social stuff' is a typical Latourian turn of phrase and it is in this sense derived from his work that I use it herein.
} 
ways to engage in digital activities such as online gaming and they act to structure a whole network of understandings of the ontology of a gameworld participant. As Latour (2005, p. 131) notes, "a network is an expression to check how much energy, movement and specificity our own reports are able to capture. It is a concept, not a thing out there. It is a tool to help describe something, not what is being described." This follows Dolwick's (2009, p. 42) take on research via ANT:

Network is similar to an exploratory rhizome. It is meant to help the researcher see how social units are related and arranged (or rather to see their potentialities). Ultimately, the point of writing research accounts and using a 'network' metaphor is to be able to show all of the hard work that went in to making something: a technology, a science, an artefact. It is a way of accounting for the social. Thus, here, social is not a special ingredient, or domain of reality, implying humans only. Instead, it refers to associations of radically heterogeneous actors.

Thus, per Mol's approach, how is gameworld participation performed in and through these associations and understandings? If these understandings are seen to exist via associations between gaming, leisure, labour and being, how many associations and understandings am I able to find and describe, through my own gameworld participation? Through my own digitality? Through my observations on others and via my interactions and conversations with others? This is my point and purpose. 


\section{Conceptual Terminology\& Literature Overview}

Leisure as a distinct, bounded area of human existence is a modern invention. Despite the fact that leisure and labour are not clear cut categories of experience or activity in actuality, the literature presents leisure and labour activity as strongly opposed to one another. To do justice to my topic and aim, then, I will lay out a general background here of some of the literature around leisure and labour, with the intent of laying the groundwork for my investigation and mussing up of their boundaries, as it pertains to gameworlds. I will begin by using the leisure literature to historicise the notion of leisure, and discuss the ways in which leisure has been understood in sociology and in everyday parlance. I will continue on to an account of perspectives on labour, starting with the theories of Karl Marx and moving to critical and leisure theorists. I will finish off this literature review section with a third perspective, an overview of the literature I am adopting to frame a stance on neoliberalism and governmentality. For this, I will rely heavily on the work of Nikolas Rose and Timothy Mitchell. An understanding of how I am framing neoliberalism and governmentality is crucial to contextualizing my main argument about associations between gaming and digitality and leisure.

This section is structured as a set of terminology definitions, followed by a review of the relevant literature ${ }^{3}$ that has informed my thinking on the leisure/labour dialectic and on the current socio-political context of modern life. Given the jargon that exists in the WoW

\footnotetext{
${ }^{3}$ I must comment that inclusion of any theorist in this thesis, either in the literature review or in the analysis, is not intended to indicate a fulsome understanding or adoption of their entire scope of thought. Rather, I ascribe to the Foucauldian assertion that theory is a toolbox; I wilfully use the parts of any theorist's work that are necessary and applicable to the job at hand and ignore the rest. I agree with Rose's proclamation: "Concepts are more important for what they do than for what they mean. Their value lies in the way in which they are able to provide a purchase for critical thought upon particular problems in the present" (Rose, 1999 , p. 9). In this sense then, reading and invoking theory for me operates as a kind of muse, opening up new avenues for thought and paying homage to the theories and theorists who were my inspiration.
} 
gameworld, and which is necessary to use throughout this thesis for proper ethnographic thick description, I have included a glossary of gameworld and gaming terms herein as Appendix I.

\section{Terminology}

\section{Inhabitant Over Gamer}

Outside of my introduction, I have chosen deliberately to use the term "inhabitant", rather than using "player", "gamer" or the more sociologically neutral "participant". Gamer as a descriptive term is fraught with tensions around identities, roles, power relations and other such well-trod research preoccupations. Because I did not want to explore role theory, identity theory and management, or human-avatar dependencies, and because I am aware that online identity is a large area of study within the field of digital culture studies and game studies, I needed a term that would consciously allow me that avoidance. I also needed a term that would delineate the difference between massively-multiplayer online gameworlds (MMOG) and other types of games. MMOGs are persistent environments and "fundamentally social spaces" (Taylor, 2006, p. 10) . To become an inhabitant in an MMOG like WoW involves more than just skill at manipulating controls to accomplish tasks and finish the game (though arguably WoW can never be finished). It also involves spatial awareness, scope management, time and money management, and a huge quantity of social skills. It is nearly a truism by now, in game studies, to point out that MMOG environments are as much about the community of the others in the world as they are about the actions that take place there (Taylor, 2006). Thus, my choice of the term inhabitant foregrounds the active lived social and political nature of the world for the actors involved and it backgrounds the package of general social and research assumptions involved in using the more familiar term, gamer. This choice should not be taken to assume that the 
inhabitants do not consider themselves gamers, or that this is not a desirable term more generally.

\section{Digitality Rather than Virtual Reality}

Much ink has been consumed explaining the differences between the virtual world and the real worlds. For reasons that will be clearer as this thesis progresses, I avoid this incorrect ontological posturing. Instead, where absolutely necessary, either to manage the expectations in the minds of my readers or to insert comments around fieldwork results or to take part in existing academic discourse, I choose to designate between the state of living in different realms of a single existence rather than to differentiate between supposedly correct/valid and incorrect/suspect realities. I borrow the term realm not from philosophy or geography, but from my game life. I take the inspiration for the term directly from the gameworld of WoW, in which the various computer servers on which inhabitants are distributed are called realms and each realm presents similar but different instances of a gameworld otherwise understood to be identical. Thus, I choose the term digitality to replace the erroneous term virtual reality. This term highlights that existence in digital spaces is a state of being in a certain realm of life, as opposed to an implication in a suspect method and mode of living. The digital places are also deeply human, intensely social spaces, and it is this twinned character of human sociality that I wish to highlight through the term digitality, and its corresponding shorthand, 'the digital'.

\section{The Social and Sociality}

Following Latour (2005, pp. 4-5), I take issue with sociology's constant invocation of the term 'the social'. Latour remarks, somewhat wryly, that this discursive entity sociologists use seems somehow to take into account simultaneously each of the following meanings: a social 
context; a domain of reality; a group of participants; a discipline of study; a group of privileged analysts; and a method of studying each of the former, alone or in concert. Given the multivariate meaning, how am I to be able to use it in an appropriate way, and extend it to digitality, without resorting to the language games Latour accuses sociology of when invoking the social? I find my guidance via Rose (1999). He tackles the thorny notion of what 'the social' is and what the word social has come to mean in everyday understanding. Rather than the standard messy understanding of the term via sociology, as a reified force with its own logics and entities, he argues via Deleuze that the social is a specific sector of life:

[It] does not refer to an inescapable fact about human beings - that they are social creatures - but to a way in which human intellectual, political and moral authorities, within a limited geographical territory, thought about and acted upon their collective experience for about a century (p.101).

Keeping this in mind, I will remove the genealogical intonation and retain the action-oriented idea of how individuals and group see the results of their collective action. Where possible, to be quite clear, I will avoid the use of the term "the social" because of the reification it suggests, and will instead use the term sociality, to highlight the processual nature and fluid dynamism of this aspect of human life.

\section{Leisure and Gameworld Careers}

The notion of a career is commonly understood as a progression of an individual's work life, along a defined purposive labour path that has set-out goals, expectations, roles and compensation attributed to it. Entwined within this definition is a notion of time, of action and of 
boundaries. Careers take place over time, usually the span of an adult's prime working years. They are singular, in that each adult has only one career ongoing at any period. In leisure theory, the term leisure career is borrowed from occupational sociology to describe the attitude, approach, intent and seriousness with which an individual may treat their set of dominant leisure activities, within a frame that Canadian sociologist and noted leisure studies scholar Robert Stebbins calls serious leisure (2008). Kjolsrod (2009, p. 375) says of serious leisure, "Like work, it is a substantial activity; nothing is laid back about it. Like work, it is systematically pursued, even to the point of developing lasting careers". Careers in leisure, as in work, owe their existence to personal efforts based on specially acquired knowledge, training and skills. Moreover, actors in both areas tend to identify strongly with what they do. This identification springs from their efforts as well as from the rewards they reap.

For this thesis, the term leisure career is particularly apt. I usually encountered people speaking of their gameworld participation as a "life" or a type of "living"; indeed, it is a term that has crept into my own vocabulary, as I speak to people about my "life in WoW". I posit that gameworlds present their inhabitants with a choice of options to create a gameworld career. Across multiple characters and guilds, and via the crafting and social systems of the gameworld, how that career plays out is enabled and constrained as much by the inhabitants' approach to their gameworld life and by the general social environment of the gameworld as created by players, as it is by the rules and structures of the gameworld system and software. I will elaborate on this further in the analysis section. For definitional purposes, I play off the academic leisure literature's definition of career and I define a gameworld career as the span, scope, attitude, approach and investment of an inhabitant's gameworld life. While this thesis deals particularly 
with WoW life, it should be noted that individuals can have more than one gameworld career at a time, if they have made the choice to be involved in more than gameworld (e.g. Lord of The Rings Online as well as World of Warcraft). This is one of the aspects of a gameworld career that differs from other kinds of leisure or labour careers.

For the purposes of terminology, I define a gameworld career as an attitude, approach, style of sociality and degree of dedication to the gameworld path chosen by the inhabitant. At a high level, that career may follow any one of five themes - grinder, quester, socialite, raider, or PVPer.

\section{Perspectives on Leisure and Labour}

Originally I intended to present separate and discrete perspectives on leisure and labour. However, in attempting to tease out the differences, I found the literature on leisure almost universally engaged in a study of binaries and absolutist contrasts against notions of labour. It is therefore apparently necessary to discuss the two herein in concert, rather than attempting to extricate them and cordon them off into distinct and separate discussions.

Sylvester (1999) notes that the idea of separating human existence out into these master spheres of leisure and labour arose out of class stratification interests in Greek and Roman times and this persists today. The dominant theme in the sociology of leisure is the differentiation between two master types, spheres or categories of everyday human life, and then a whole variety of subsets of each of these realms (Sylvester, 1999; Iso-Ahola \& Mannell, 2004;

\footnotetext{
${ }^{4}$ I am aware that Richard Bartle (1996) has written a now-classic piece of games studies work around labelling players according to their play style and motivations. Much work has been done to adapt, alter, expand or contest these typologies since his article was published, and his typology seemed lacking in several areas when I attempted to apply it to the WoW gameworld . Consequently, I am choosing to use my own terms that seem to match more closely the way in which inhabitants pursued their careers within WoW.
} 
Hemingway, 1999; Mannell \& Reid, 1999; Moorehouse, 1989; Frisby, 1989). While

Moorehouse does note that the divisions between the two master realms is a subjective and personal interpretation on the part of everyday individuals and analysts alike, much of the literature nevertheless perpetuates a formal boundary between the two. The financial and subsistence activities are seen to form the sphere of work and the pursuit of pleasure and sociability are positioned as the sphere considered as leisure (Moorehouse, 1989; Rojek, 1989). In both general parlance and in much of the leisure and labour literature I encountered, work is intended to be financially productive, producing a wage or salary that allows the worker to obtain the things she needs in her daily life, such as food, lodging, clothing, etc (Moorehouse, 1989). In contrast, as noted by Rojek $(1985 ; 1993)$, leisure is generally considered to be unproductive, in that it produces no monetary capital..$^{5}$ Leisure is seen to lead mainly to the strengthening of social ties between friends and family, as well as contributing to the release of stress via endeavours deemed to be 'fun' (Blumer, 1954Iso-Ahola \& Mannell, 2004; Iwaski \& Mannell, 2000; Kelly, 1999; Moorehouse, 1989; Rojek, 1989; Stebbins, 2005). In this commonly understood binary context, leisure is never labour and work is never play. ${ }^{6}$

The idea of studying leisure as an intrinsic domain within sociology started appearing post World-War II, as a result of the "increase in disposable income and free time" (Rojek, 1985,

\footnotetext{
${ }^{5}$ It is worth noting that while Rojek remarks this to be the case, he is not saying he agrees with this state of affairs in the sociology of leisure. He argues most cogently in Rojek (1985) that the most often used approach to the sociology of leisure suffers from an excess of social formalism, which arises "from the failure to situate leisure relations in the context of the history and general power relations of capitalist society" (p. 7) and he notes that the debates around what leisure is within the modern capitalist context most often fails to recognize the role of leisure in contemporary capitalist power relations, instead choosing to engage in stuffy battles of competing sociological paradigms, or what he calls "a state of multi-paradigmatic rivalry" (p. 5).

${ }^{6}$ This formal and fairly strict division between leisure and labour is problematized often by Rojek in his various writings (most cogently in Rojek, 1985), and the artificiality of the divide is summed up rather nicely by Moorehouse (1989, p. 15), where he notes that most scholars of leisure and labour "adopt an extremely unrealistic view of what paid labour was and is" and this then feeds out into equally unrealistic views of the ontology and actuality of leisure.
} 
p. 2) that was the result of widespread technological industrialization and the proliferation of the marketing and consumer goods sectors. The study of leisure within sociology expanded widely in the literature of the 1960s, chiefly via the work of community studies scholars and those interested in occupational sociology (Dumazedier, 1974; Kelly, 1974; 1999) and much of the work carried an interest in policy issues (Rojek, 1985). Also, too, with an emergence of tourism as a global industry, marketing and business departments became intensely interested in the concept of consumer leisure (Kelly 1974, 1999; Kjolsrod, 2009; Rojek, 1985). At that time, leisure was seen as a derivative of the economic sphere of life, as part of the "reward structures of a social system" (Kelly, 1999, p. 54). With the North American economic focus moving from industrial production to finance and capital management in the 1970s and 1980s, the decline of the official normative work week also moved down to 40 hours a week from 80 in its industrial revolution high. As a consequence, notions of leisure as "leftover time to be filled with activity other than work and required maintenance" (Neumeyer \& Neumeyer, 1958; as cited in Kelly) began shifting towards the idea of leisure as a domain of social life, with its own dimensions, requirements and challenges (Kelly, 1974; 1978; 1999). In this sense, then, leisure was as much about action and sociality as it was about time, and the sphere of leisure came to be seen in sociology and cultural studies as a realm as important as and equal to that of the work realm of human life. The more recent alterations to this view show an intensification of this trend, with leisure now often regarded in the western context to be one of the two most important aspects of human life, with the other being family life (Kelly, 1999; Roberts, 1999; Stebbins, 2005; 2008), leaving labour (understood as paid employment) trailing behind these. Kelly (1999) notes that while the North American tradition of the sociology of leisure tended to follow functionalist or 
structuralist lines, the emerging critical studies focus in the UK from the CCS tradition of the 1970s and 1980s saw leisure as a realm of human life deeply woven into the power structures and dominant ideologies of any given society.

Chris Rojek (1983) identifies two dominant streams of thought as it relates to the idea of leisure, and he sums up them up as deliberately constructed dualism between emancipation and demoralization (though he notes the dualism is rather messy and leaky). On the one side, there is the stream that sees leisure as the freedom from physical toil, with a corresponding emergent ability to engage in activities that stimulate the mind and the spirit. As some have noted (Beatty \& Torbert, 2003; Hunnicut, 1990; Kjolsrod, 2009; Sylvester, 1999), this stream of thought pays homage to Greek and Roman philosophy and extends into the Frankfurt school theorizing and in the early works by leisure studies scholars. In this stream, the concept of leisure harkens leisure back to the classical ideal of leisure as "freedom from a less important activity for a more important activity" (Hunnicut, 1990, p. 213). The more important activity is usually considered to be anything that expands the mind and spirit of the individual. Kjolsrod (2009) notes that for Cicero the idea was one of "leisure with honour" (p. 372) for all noble people. Beatty \& Torbert say of Aristotle that his philosophy saw leisure as "activity generated by an inner attitude of voluntary engagement and inquiry" (p. 241).

This classical sense of leisure has influenced the thinking of leisure as activity and attitude. Sutherland (1957) writes that this classical influence is evident in both Mumford and Veblen's writings, in which leisure is the state of mind of a specific socio-economic class, and that state of mind is intended to allow an individual to create experiences and objects of their own volition as they see fits their station in life. This coupling of attitude with proper activity 
therefore enables the cultivation of an individual's proper inner life (Hunnicut; Sutherland), which can be brought out with the right attitude and put into practice via action. To put it more succinctly, "leisure becomes leisurely from the inside out, not the outside in" (Beatty \& Torbert, p. 243). It is leisure as attitude (Beatty \& Torbert) and it is emancipatory in that this selfactualized right attitude is considered to be the way to personal freedom and peaceful existence in the world.

With this attitudinal emphasis in mind, Rojek (2004) notes that within this stream, leisure as a notion or actualized concept is still inseparable from a comparison, condemnation or contradiction to work or labour. Several writers (including Adorno, 2002; Beatty \& Torbert, 2003; De Grazia, 1962; Pieper, 1999; Roberts, 1999; Shogan, 2002; Stebbins, 2005; 2008; Veal, 2004) have commented that in the modern adaptation of this stream of thinking on leisure, the leitmotif of this idea of leisure is the freedom from paid drudgery, time constraints and obligations, or freeing up one's time to engage in higher-minded pursuits of one's own desiring and choosing. This combination of desire and choice is what creates pleasure in an activity, and pleasure is seen as a hallmark of leisure (Elias, 2000; Stebbins, 2005).

Consonant with this, the second, almost oppositional stream that Rojek (2004) delineates is one of demoralization. In discussing this dualism and tension between leisure and labour, he notes that many disciplines, most notably political economy, explains that labour or "paid employment" as the a priori of leisure (p. 51). Rojek suggests that the tradition within the sociology of leisure continues to bear the traces of its political economy origins, given that the key debates in the field remain squarely focused on the relationships between work and labour. 
Both Rojek and Kelly (1999) note that this is true, regardless of what flavour (feminist, postmodernist, post-structuralist) the debate is situated within.

Certainly for Marx (2007), labour is a key preoccupation of modern life. In the Marxian view, labour is an idea and thing as much as it is an activity. Modern labour is the "harmful and pernicious" (p. 28) contingency of capitalism that nevertheless remains the defining aspect of the difference between the human and the animal, and the natural and the artificial. It is the classical political economy idea of labour as "the sole constant price of things" (p. 27) that Marx says has been used to justify the modern capitalist economic way of life, in which labour is naturalized and accepted as inevitable, and leisure is optional and of less value, whereas Marx notes that labour is actually alienated human potential and suggests that the labour/leisure divide is artificial. Essentially, then, Marx is talking about specific vectors of power struggle that shape and align along certain spheres of activity within human relations.

Along these lines, Rojek (1985) notes that capitalism is characterized by a specific organization of relations that seeks to maintain certain divides between labour and leisure in order to solidify specific power relations. Rojek says that "capitalism is based on the division of interests, individual competition, and the ideology of acquisition...[and] leisure forms both reproduce and undermine these principles" (p. 7). There is definitely the suggestion in Marx (2008) that labour is a structuring principle for the modern time sense. Marx says that labour divides time into rationalized portions (2008); time which can then be actualized into a commodity and sold by capitalists as a thing which is actually stored-up labour (2007). He notes that time spent not labouring is supposed to be used only to rejuvenate the self for the purposes of labour, and when a worker "consumes his disposable time for himself, he robs the capitalist" 
(2008, p. 149). Leisure is time left over that does not need to be spent labouring, but must still be spent in the service of labour, to renew the body, mind or soul to return back to their labour refreshed, energized and capable. As such, since the entire reality of workers is supposed to be tied to their labour, there is a moral prescription inherent yet unspoken within leisure to only spend as much effort as is required to rejuvenate one's self for return to labour, given that labour is the primary aspect of human life. In this sense, as Adorno (2002) points out, leisure time is just as reified and structured by capitalist principles as labour.

Rojek (1993) notes that these divisions were supposed to propagate a rationalized and clearly understood idea of the proper moral life, yet these attempts were always subject to contestations by the very processes, structures and group that were interested in maintaining the original divisions. As Rojek writes:

"In the period of early capitalism, bourgeois culture sought to lay down simple moral principles designed to achieve self-realization. Work was divided from leisure, private life from public life, the nation state from other nation states, men from women, in an attempt to produce a rational, stable order of things. But the development of bourgeois society ceaselessly undermined this order by turning principles into contradictions and divisions into chaos" (p. 99)

Within the Marxian political economy literature, labour and leisure are both beholden to capitalism and it is the needs of capital and the bourgeois class that make the distinction and separation between the two necessary. Outside of this classical literature, however, within the leisure studies literature I have already cited, and aside from Rojek's work, there exists a curious 
silence or ignorance about the ways in which capitalism and its modes of production constitute both the realm of labour and the realm of leisure. The literature suggests that is only via leisure that individuals can escape the tyranny of work, as if the capitalist modes of production do not equally structure and influence leisure time as well. In this literature strain, leisure is supposed to be the place for individuals to be free, to exercise their unique interests and capacities, by engaging in activities that are not necessarily financially productive (activities that Adorno refers to derisively as 'hobbies'), but are instead ways of escape from labour and from the capitalist mindset.

This myth of leisure is a theme highlighted then problematized by Adorno (2002) and taken up by Rojek $(1985,1993){ }^{7}$ Yet despite Adorno's critique of this notion of leisure, which he labels "organized freedom" (p.190) in a deliberately ironic tone, the idea of leisure as freedom, rejuvenation and redemption nevertheless seems stubbornly present in the leisure studies literature. It is from this stream of thought that a great deal of the most recent academic work is done in leisure studies, be it in research on the psychological effects of overwork or 'burnout' (Iso-Ahola \& Mannell, 2004; Maslach \& Goldberg, 1998), examinations on the stress relief potentials of leisure (Iso-Ahola \& Mannell, 2004; Iwaski \& Mannell, 2000), or theories around the ways in which leisure activities and experiences parallel work experience (Silverman, 2006; Stebbins, 2008; Wilensky, 1960). Given that the Latin root of the word 'leisure' is licere,

\footnotetext{
${ }^{7}$ One example that Rojek provides which illustrates this nicely is eating as an activity. At its base level, eating is a sustenance activity that is fundamental and necessary to human life. Yet it is also essential to the reproduction of capitalist relation s, for eating sustains the human body and perpetuates its ability to engage in labour. Simultaneously, however, it is a capitalized, commoditized and moralized leisure activity, as seen in the modern proliferation of restaurants, cookbooks, television shows, food magazines, diet gurus and eco-moral philosophies of food (e.g. 100 mile diet). While he does not quote Elias, nevertheless, Rojek is extending aspects of Elias' (2000) arguments around eating as a central problematic in the social organization of human activity and human power relations.
} 
meaning to be lawful or allowed (Rojek, 1985), it is interesting that in these views, so much of the idea of leisure is based on the idea of time spent without obligation, or at least without what Stebbins calls "disagreeable obligation" (2008, p. xii) and then later goes on to distill more completely into the idea of "uncoerced behaviour" (p. xii). Following both Adorno's and Rojek's (1985) skeptical views of free time, hobbies and the pursuit of leisure, this notion of leisure as uncoerced, freely chosen, restorative and inconsequential will be problematized when I present my ethnography of digitality within the gameworld of WoW.

\section{Perspectives on Neoliberal Being}

When I speak of 'being' here, I am invoking both the obvious philosophical concept of state of existence, but also the more socio-political sense of the term, as it relates to action and experience within a given power situation. Specific to my invocation of the term being then is the notion of action, conduct and power within the modern market and state. It is the notion of being in and of the world, simultaneously creating it and being shaped by it, controlling and resisting the forces at play

This socio-political notion of being is embedded deeply then in what can be construed as a neoliberal context. Neoliberalism as an idea or concept has a multi-faceted background and meaning. It is considered variably to be a theory of rationalized economic practices (Dean, 1999; Harvey, 2005; Mitchell, 2002), an approach to the management of state, national and private interests (Rose, 1999), a pragmatist philosophy towards freedom and governance (Harvey; Mitchell; Rose, 1999), a reaction to the left-tendencies of liberalism (Kendall, 2003; Rose) or a technology of power and identity management (Brown, 2006; Ong, 2006; Rose, 1999). Kendall (p. 6) sums up the elements of neoliberalism: 
To a certain extent the philosophical differences between liberalism and neoliberalism are slight: it is certainly the case that all the elements of neoliberalism are contained within liberalism - responsibility, self-government, private rather than public ownership, an essentialization of the market, the attention to practices of freedom of the individual, and so forth.

Regardless of what flavour or combination of flavours is adopted, the theme that runs through all the theorists cited is the idea that neoliberalism is a highly rationalized political force and social ethos that shapes processes and conducts in the modern realm. As a central preoccupation, neoliberalism holds that freedom is the right of every individual, but as Harvey (2005) notes, it is a bastardized notion of freedom that ties itself to an economic predetermination and to the notion that the market will be the source of freedom and selfactualization; economic freedom, then, becomes the only path to the ultimate goal of neoliberalism: Progress. The twin concepts of progress and freedom manifest both as an intensely localized attitude inculcated into individuals from the moment they start to play a part in the social world. But this happens via a global structuring ethos that determines possibilities for living more generally in the current age.

It is this hybrid socio-political and economic sense of the concept of neoliberalism that I will adopt for this thesis.

Accompanying ideas on neoliberalism then are ideas on human ability and power as put into action. The term stems from the Foucauldian notion that all of human conduct is understood and guided by an ever-increasing assumption of micro social control over one's person. 
Stemming from the term government, and generally understood to mean the conduct of conducts, Dean defines governmentality as "how we think about governing others and ourselves in a wide variety of contexts" (p. 209). This point is especially pertinent when it is combined with the idea of labour as both essential for expressing the innate humanity of individuals, while equally demonstrating how far humans have moved into the alienation inherent in the capitalist state of modernity. I argue that a substantial part of adult life in the western context is constrained and circulated through labour that masquerades as leisure, and this masquerade is enabled by the values embedded in the modern neoliberal context and structured according to capitalist and neodemocratic principles and values.

Rose (1999) argues that the neoliberal prescriptive context of modern life arises out of desire to lead a proper life according to specific right values. Those values shape "conduct in ways conducive to particular conceptions of collective and individual well-being" (p. 49). Apart from the obvious understanding of government as synonymous with the apparatus of the state, Rose notes that liberalism (and thereafter neoliberalism) refers not just to a type of state ethos, but more importantly and pervasively to "the activities and calculations of a proliferation of independent authorities" (p. 49). In this sense, neoliberalism functions as a kind of circulating political ethos that binds the state, the public sphere of everyday life and the private sphere of individual life up in a web of forces that direct and constrain action and possibility. These neoliberal values are political in that they express and operationalize a specific view of the uses and desirability for human action. As these values embed themselves into everyday 
understandings, Rose argues that they become part of a system of translation. ${ }^{8}$ I see this translation occurring in linkages between state directives, corporate interests, public concerns and private understandings. By the time the values are internalized and adopted by individuals, the translation process is so complex and muddied by so many footprints that it becomes near impossible for the average individual to separate from each other the ideas and understandings they hold from their origins and influences. For this reason, if the circulating knowledge system that is neoliberalism can be understood to be a macro-actor within and around human life, the values that circulate from this system can be understood to be the values of modern life.

What are these values? While no single source lays them out in so bald and obvious a list, distilling ideas of neoliberalism primarily via Harvey (2005), Rose (1999), Ong (2006) and Mitchell (2002), I understand neoliberal values to be as follows:

- the rightness of capitalist market dominance;

- the appropriateness of evaluating objects, materiality and experiences via the levelling field of circulating currency; and

- the concern for individuality, freedom and self-determination.

Thus, via these values and macro-actor that is neoliberalism, I argue that understandings of how to be human in the current era are directed and constrained by the translation processes wound up in their associations, directed at the structuring notions of freedom and progress. These

\footnotetext{
${ }^{8}$ Rose is adapting Callon \& Latour's idea of translation here. In these theorists' pure sense, translation refers to the transposition of understanding and action from one actor to another. Via this concept, Callon \& Latour suggest a need for sociologists to attend to the power position that is involved in the act of translation and association. (See Callon \& Latour, 1981).
} 
associations shape ontological understandings of action possibility, appropriateness of certain actions and ideas over others, and thus for potentials for being more generally.

\section{Methodology}

"Method goes with work, and ways of working, and ways of being"

(Law, 2004, p. 10)

"It is time for researchers to realize that they must position themselves as participants in the process of development by placing their results at the disposal of the online communities that they study"

(Feenburg \& Bakardjieva, 2004, p. 41)

\section{Intent}

A large part of process of doing this research and writing this thesis was an attempt to understand and operationalize the hybridity of methods and approaches demanded of sociological research generally and digital environments specifically, as it relates to my research questions. Because of this, I am paying particular attention to methods and ethics in this section and will write at length about the driving forces behind my own synthesized approach. My ethnographic and content analysis approach is informed by the work of Norman Denzin, Bruno Latour, and John Law.

What is a gameworld? What does participation in a gameworld look like? These are the questions I first started working with when I first entered the WoW gameworld. Over time, as is always the case in ethnography, my questions shifted, deepened. I started questioning why it was that, in everyday social understandings, engagement in MMOGs was perceived to be a less valid form of leisure and social interaction that other possible activities within other environments. Because of this, two new and more nuanced questions emerged: How does a massively- 
multiplayer online gameworld (MMOG) such as World of Warcraft (WoW) refute or reflect the capitalist leanings of the dominant neoliberal culture in which it is situated? How does this understanding of gaming as suspect leisure feed into the everyday understood associations between gaming and leisure, gaming and labour, and gaming and social being? Ultimately, these latter two are the questions that drive the investigations and explanations in this thesis.

\section{Approach}

Given that my aim in this project is to address my primary and secondary research questions, as framed above, I have chosen to use ethnography. I argue that ethnography is, at its core, a triangulated approach, which combines direct immersion and participant observation, and qualitative observation and analysis. I based this research approach on Denzin's (2009) triangulation approach, but I acknowledge that the reality of its presentation here more closely aligns to Law's methods assemblage approach.

In Denzin's view, research methods "represent different means of acting on the environment" (p. 298) of the research interest. Different means of action require different lines of inquiry and investigation. Each of these methods of following the lines of action will produce different stances on the understanding and interpretation of that environment. As Denzin (p. 298) states:

Each research method reveals peculiar elements of symbolic reality. When a sociologist adopts a method, his [sic] definitions of that method serve to make his final observations in some way different from those of any other user-past, present, or future.

The reality that I present, here, via my observations and findings will hold true now, at the time of my writing, but can be adjusted and reinterpreted in the future, because, as Shibutani puts it 
(via Denzin, 2009), "what is called 'reality' is a social process; it is an orientation that is continuously supported by others" (Shibutani, 1966, p. 170). I like this approach, because it points to the ways in which reality is never static, but is always being affected, adapted, altered and rejected by new actors and new actions.

However, to suggest that I have triangulated my methods strongly and neatly suggests a boundary neatness between each method that does not reflect the reality of my actual research. The reality of my work occurred in a jumbled mixture of gameworld experience, game forum perusal, chat with colleagues and acquaintances and perusal of media reports. In this sense, I was often simultaneously observing and processing, recording and analyzing, and rarely was any one method or step in the research process isolated out in a linear fashion from any other. In this sense, I follow Law more closely then Denzin, in which Law says of his view of method that research in this vein is "a risky and troubling process", one that takes "time and effort to make realities and hold them steady for a moment against a background of flux and indeterminacy" (Law, 2004, p. 10). Research is truly practice in his view, in the sense of adding the novel and unknown to the understood, trying it out, and seeing what works. I argue that this is particularly the case when working through the quicksand nature of digital reality. Law's methods assemblage enables me to acknowledge that my topic and findings arose via an entire set of relations and knowledges, some new arising from the research experience, some old from my past, some deliberately understood and some accidentally discovered. Thus, my research reality may be relevant today, but might find different actions and responses and therefore be compared to different realities two weeks, two months or two years down the road. 


\section{Actor-Network Theory}

I have also been deeply influenced by the work of Bruno Latour (2005) specifically, and others in Actor-Network Theory (ANT) and Science and Technology Studies (STS) more generally, paying particular attention to John Law's (2003; 2004) methodological turn. I concur with Latour's call for sociologists to get their hands dirty, to get into the field and follow the actors, regardless of where that might take them. Rather than ascribing all results to some nebulous force called 'the social', Latour argues for the reverse. In Latour's take on sociology, there is no social force; there is only an aggregate of actions that sociologists then conveniently call 'the social'. He argues against a reified notion of society or a force called 'the social'. Latour asks sociologists to make up their own theories of what substance makes up this 'social' thing and from where this 'social' thing is derived, but to do so only by following the actors themselves and observing their actions and outcomes. In this sense, a Latourian approach is inherently inductive. The actors tell the researcher what is important to them, via their words and their actions. In Latour's sociology, only by mapping the controversies over group formations and identities can sociologists understand this thing called the social, because in his words, "social aggregates are not the object of an ostentive definition....but only of a performative definition" (p. 34; original emphasis).

In my use of methods and my analysis of my fieldwork, what this means is that I commenced my fieldwork without a specific research goal in mind and that I attempt to resist the urge to ascribe the causality of the phenomena and the interpretations of the actors I have followed (and of the actor I have been myself) to a mystical social force or entity. While this imposes constraints on my analysis, forcing me to not revert to ascribing causality to an 
amorphous "they" of society, it also allows me to be true to my Latourian aims in description and analysis. While this approach shares similarities to gestalt and holistic approaches to research, the major difference is that a Latourian approach or ANT sensibility makes no claims to speak for or see an integrated whole with formal boundaries and definitions.

Latour and Law both call for sociology as a practice to once again get messy; to get comfortable again with being incomplete, unfinished, chaotic, contingent and sometimes failed. Following this, I do not attempt to draw a direct causal link between the cause of the everyday understanding about gaming and leisure as attributed directly to the actions of actors $\mathrm{X}, \mathrm{Y}$, and Z. In considering the inherent incompleteness of social research, I acknowledge that I may have missed certain actors, or may not have noticed the associations between some actors. Equally, my findings may not be transferable to other game environments or platforms. Indeed, my findings may simply open up new questions, or they may fail to hold up altogether. This incompletion or failure is still a success, in Latourian sociology, so long as the actors and actions have been faithfully represented and considered prior to analysis.

Finally, when acknowledging my debt to Latour and ANT, I highlight my own approach to writing this thesis, as something that is highly reflexive, personal and situated as it is in my own webs of association as a graduate student, a gamer, a guildmate, a spouse and a friend. By using a confessional ethnographic approach, in which I foreground my stops and starts and gaps and failures and successes as a researcher and as a player, my intended aim is to remain true to the messiness that is research and to make visible the leaky boundaries and my failed attempts to police the boundaries between gamer and researcher, player and student, digital inhabitant and 
non-digital citizen. ${ }^{9}$ I intend this style to allow me to stay as true as I am able to the way Law (2003) describes ANT as a research sensibility. I have strived to present my work in a fashion that escapes Latour's charge of being a sociological vampire (Latour, 2005, p. 52), in which the gaps and failures of action are elided in the interests of a false empiricism and a neat closure of results and analysis.

At the same time, I also am aware that I violate Latour's ANT approach on many fronts, most notably the fact that I admit to having an agenda prior to starting this thesis. The act of doing this work, writing this thesis and analyzing actions in the way that $\mathrm{I}$ have done herein is political. Law notes that sociological research is always political because it always strives for an adjustment of understanding. As Law puts it, "the issue, then, is not to seek disengagement but rather with how to engage" (p. 7). Having encountered firsthand the social suspicion associated with being a WoW gamer (thereby prompting these lines of inquiry), I set out in this thesis to figure out where those suspicions come from, whether I am the only one who encounters them, and what they might say about gaming as one association among many in a neoliberal world. Because I presuppose that everyday understanding and I work at altering it through a better understanding of what has gone into forming it, my aims are at odd with Latour's purist perspective, but consistent with Law's more messy STS approach. This desire of mine to rectify a dualistic understanding of gaming as leisure puts me squarely in the camp of sociologists who engage in "emancipation politics" (Latour, 2005, p. 52), something Latour dislikes immensely.

\footnotetext{
${ }^{9}$ Denzin notes that "no scientists can ever separate their personal and public lives. They are continually thinking about, puzzling over and troubled about unsolved issues" (p. 61). I argue that this is particularly true in the context of digital games studies such as mine.
} 
Yet, following the ANT sensibility, I will nevertheless report on and consider the associations I find, regardless of whether or not they achieve my political aim.

\section{Research Environments}

This thesis project is the result of two and a half years of immersion into game worlds, starting with Lord of the Rings Online (six months), then moving to Eve Online (six months), then most recently World of Warcraft (one year, six months). I began my own MMOG gaming career specifically for academic research purposes, but I had no specific question in mind at the outset. The intent was to live in the field, so to speak, and see what issues and phenomena percolated up to my awareness and interest. It was a deliberate attempt to insert myself into the gaming field and figure out what was interesting to me sociologically, at an inductive level. At a more fundamental level, I have to admit that I also needed to acquire the skills and knowledges of a gameworld inhabitant, skills not acquired in my previous years of playing strategy and simulation games. ${ }^{10}$ The only way to acquire these was to go into the field as represented by the gameworlds and live within them.

Because I am not claiming that I was directly researching this specific thesis topic throughout my two-plus year MMOG gaming career, I have chosen herein to foreground my latter year of WoW participation and use WoW primarily in my direct cited research and examples.

\section{What and Why WoW?}

${ }^{10}$ Some examples of past games I have enjoyed: Civilization III; Ages of Empires; SimCity; Caesar; and The Sims. All of these are PC-based games, but all are single player. While they have a gameworld, it is highly static, given there is no interaction between the gamer and others within the gameworld. 
In choosing a specific game world in which to do my fieldwork, I considered several games. I chose World of Warcraft because I had been hearing about it for years and was curious how it differs from the other MMOGs I had tried. Quite simply, WoW is the industry's juggernaut. Blizzard Entertainment is the owner of the Warcraft franchise titles, which includes the online video game, card games, board games, previous single player video games and other additional products, from magazines to fiction novels to 'swag' ( $\mathrm{t}$-shirts, mugs, etc.). Blizzard released the World of Warcraft online game in 2004, and it quickly went on to dominate the MMOG marketplace. Wired magazine reporter Earnest Cavalli notes "estimates on the game's monthly revenue often tops $\$ 100$ million, and the game boasts subscriber rates that eclipse its closest competition by a factor of 10 " (Cavalli, 2008). The most recent statistics released by Blizzard claim 11.5 million plus active subscribers, with an active subscriber defined as: individuals who have paid a subscription fee or have an active prepaid card to play World of Warcraft, as well as those who have purchased the game and are within their free month of access....The above definition excludes all players under free promotional subscriptions, expired or cancelled subscriptions, and expired prepaid cards." (Blizzard Entertainment, 2008)

The massive number of subscribers translates to hundreds of fan websites, chat rooms and forums. Conversations about WoW can be heard in restaurants, movie theatres, university campuses and elsewhere. This huge amount of talk meant that I had heard the comparisons made between MMOGs, and it seemed to me that all other games were compared to WoW in one way or another. From an academic standpoint, this enormous quantity of activity in and around the 
game translates to a rich and varied landscape of content that I can use to understand the world of WoW as both an environment and as a leisure career.

Finally, in many of the media reports ${ }^{11}$ I read about the dangers, ills and risks of gaming online, WoW is singled out as the penultimate dangerous game and the gamers who played it were often written about as social outcasts, deviant members of society who subsumed an inability to cope with the vast modern social world by playing a game of fake and fantastical life. When I brought up my interests in video games to non-academics and non-gamers, WoW was almost inevitably cited as the worst example of a useless and stupid pastime that addicted innocents, murdered marriages and consumed otherwise productive lives. All of this talk and worry and teeth-gnashing sparked my curiosity. What is it about WoW and those who play it that is so threatening?

\section{Ethnography}

The core research method I used for this thesis is ethnography, primarily auto ethnography. At its core, ethnography is a detailed description of humans, their environment, their actions and their meanings (Schwartz \& Jacobs, 1979) The purpose of it, as succinctly described by Altheide (1987, p.66), is to capture the ways in which "human beings [are] engaged in meaningful behaviour". It is both an ontological stance on research and a methodological approach to doing research. Ethnography as a method follows a researcher's specific stance on how to qualify or quantify the individuals and people, interactions, environments and phenomena

\footnotetext{
${ }^{11}$ Some examples: Beaumont (2009), Bell (2009), Benedetti (2007), Kennedy (2008), Matthews (2007), Modine (2009), Richford (2007), Shea (2008), Smith (2008), The Local, (2008), and Tanner (2007), For a good history of the general video game coverage controversy in the media, see Gonzalez (ND) and for a counter-view of the benefits of videogames for children, see Jones (2002).
} 
that the researcher wishes to better understand. It is a combination of inquiry, discovery and explanation (Maanen, 2004).

Ethnographic research seems easy enough to do, at the outset of a project. Find a world or group in which you, as the researcher, are able to integrate yourself. Then you go out and live within that environment for a determined period of time. You intend to maintain a kind of objective reflexivity, in which you immerse yourself, yet maintain enough of an analytical distance with which to be able to critically observe people, interactions, potentials and outcomes. You write copious field notes, chronicling and cataloguing your observations. You strive to not analyze during this immersive phase. Once you have gathered enough data, enough observations to act as bedrock for analysis, you withdraw from the community and environment. You then immerse yourself in the literature around your field and environment of study, and begin to compare your notes and observations against those of others, from those who similar research or who share similar viewpoints. As you write about the similarities and differences, you begin to analyze your work around and through these comparisons. What emerges from all of this is your finished written product, be it a journal article, research report or graduate degree requirement.

This is the textbook way of conducting ethnography. It is also a fantasy. Research rarely ever flows as neatly as the fantasy described above. It never occurs in this naive, linear and straightforward fashion. Rather, ethnography more closely resembles "an intense epistemological trial by fire" (Maanen, p. 427). Far from being purely empirical, ethnographic practices are threaded through with power stances, viewpoints and personalities, turning the ethnographic endeavour as much into a thickly descriptive storytelling situation as it is a pure reportage of people, events and details. As Maanen points out, ethnography is a highly diverse and multi- 
faceted way of doing social research. The written and disseminated result of ethnographic research is a kind of documentary of a specific set of moments observed and experienced by a researcher, but always filtered through that researcher's knowledges, whether intentionally or unintentionally (Denzin, 2004; Maanen, 2004; Stocking, 1985). It contains potential truths via descriptions (Latour, 1987), and those descriptive truths are always open to re-interpretations and adaptations of their analysis (Denzin, 2004). Ethnography is therefore inherently political. It always revolves around an object-site that is grounded in subjectivity and bound up in an articulation of a power situation, with the whole amalgam threaded, punctured and shaped by relations of ontological production. Or, as Maanen puts it, truth "is a rhetorical category" (p. 434).

In this sense, the notion of the researcher as impartial observer is false within ethnography. By necessity, the ethnographic researcher must be both actor and observer, simultaneously: thus, always an amalgam of insider and outsider; always a subject and an object. It is equally false to perceive the research environment as being a kind of flat field, over which the researcher can hover, part of it yet still removed. Latour (2005) argues that not only is this false, it is also inappropriate and damaging to the sociological endeavour. Rather than being above the action and attempting to capture the field in its entirety, all a researcher can and should attempt is follow along behind the actors and describe their actions.

While it is considered to be a truism in social research that a good and proper researcher resists the urge to 'go native', and actively and constantly declines from becoming immersed fully within the environment they wish to study, the reality of any ethnographic project puts the lie to this. I would take this a step further. I argue along with McKee \& Porter (2009) that it is an 
impossible to maintain researcher distance from the field and participants when doing ethnographic research around digital environments, particularly MMOGs. Within an MMOG, there is no way to designate one's avatar as a researcher. ${ }^{12}$ There is no way to stay outside or behind the players or the action in the gameworld. In order to observe, researchers must participate fully. In order to participate, researchers must be inhabitants, and must act as inhabitants. The mechanics of a gameworld are such that researchers could never gain entry into the environments, actions and outcomes of the world without themselves being fully a part of that world. Thus, researchers have to go native - there is no other choice. This question of objectivity versus representational competence is something McKee \& Porter remark to be one of the major debates in game studies methods. They note that many game studies researchers believe that one must play in order to truly be able to understand and describe gameworlds and their inhabitants. ${ }^{13}$ It is a debate that is simultaneously about ontology and ethics. I find it interesting that this debate is partly responsible for the fact that a large majority of games studies research done to date is ethnographic research. This ongoing debate is no different, though, at its core, when taken against the debates within sociological research around ethnographic fieldwork versus other methods. While a complete analysis of this debate is certainly outside my scope here, it is necessary to keep this debate in mind, for it plays into the stances found in the various threads of digital research that I will lean upon herein.

12 Name choice is the only potential way of signalling researcher's status as a researcher. To be sure, I could have chosen to create my character with a name that says, for example, "TamaraRsrchr", but given the other issues mentioned herein, that still would not have done much, and would have actually appeared nonsensical to most of the rest of the game world's inhabitants.

13 Indeed, three of the leading researchers in the field, T.L. Taylor (IT University, Copenhagen), Mia Consalvo (MIT) and Bernard Perron (Université de Montréal) are avid gamers and gameworld inhabitants. T.L. in particular is an accomplished ethnographer and she writes her work via her own perspectives as a hybrid researcher/inhabitant. 
As Denzin (2009) puts it, sociologists "must accept the fact that their own experiences probably provide the most important source of data for their theories" (p. 61). In light of these two debates around the political nature of ethnography and the inability to stave off being a game world native, wherever thick description is called for in this paper, I have partly followed a confessional autoethnographic style. This is an approach nicely described by Maanen (2004, p. 431):

Confessional ethnography is a genre of fieldworkers' trials and tribulations that moves a reader's attention from the signified (the studied culture) to the one who, quite literally, signifies (the ethnographer). The research process itself-fieldwork-becomes the focus of an ethnographic text. Its composition rests on moving the fieldworker to center stage and displaying how the social researcher came to know a given social world.

My intention in using this confessional style is to highlight my own conflicted hybrid stance as both researcher/player and as a writer/social activist, and to try to remain as true as I can to my ANT perspective. As a researcher, I have struggled with the requirements to document my fieldwork. In more classical fieldwork, the researcher would be able to observe the actors in their environment and take notes while doing the observations. Game worlds do not afford that luxury, or at least not in a straightforward method. To observe, one must be a player. Yet, the requirement to be a player involves a host of obligations and requirements that are contrary to the prescribed neutrality of the social scientist. First and foremost, being a researcher/player means playing my role in any quest or instance group, and performing all functions according to my 
class. ${ }^{14}$ Playing pure observer would never net me admission to the groups that head into instances, because a dead observer means a dead group and a very short lived interaction with the group and environment. I also have to be actively aware of the constant dangers of the game environment and know how to avoid or engage in them; a dead character means a sidelined researcher. ${ }^{15}$

What this does to the research context is to force the researcher to do one of three things while conducting the actual fieldwork portion of any project. As technology advances are now allowing for filmic-style recordings of anything happening on a given computer (provided the researcher has the memory and storage capacity in their machines to enable it, of course), one method of escaping this bind would be for the researcher to film their game sessions as they play, then return to the scene by watching the recordings with an analyst's stance. ${ }^{16}$ While time consuming, this approach may well produce the most accurate results. Another method that is more common in game studies is to play for few hours, taking screen snaps on interesting occasions, then stop the session, and write reflexive notes on what has just transpired. This is a good compromise generally, and this is the method I most often used, but it must be understood that a lot can transpire in those few hours, and some interesting action might be missed. This is especially true in situations where the play session cannot be stopped at the researcher's whim. ${ }^{17}$

\footnotetext{
${ }^{14}$ DPS/healer/tank are the options. In my case, I am almost always a DPS damage dealer.

${ }^{15}$ Admittedly, playing dead became an unexpected and useful way of observing while playing. This was most true in my own multiple failed attempts to master the various bosses of the WoTLK expansion Naxxramas instance, particularly Heigan and his plague dance.

${ }^{16}$ This film-then-analyse is something I did not do while working on the material for this paper for a variety of reasons (my technology setup being primary here), but which in hindsight I would like to try for future games studies work.

${ }^{17}$ In my case, this was an issue when I was participating in multi-player raid instances like the WoTLK Naxxramas instance, which has 15 boss monsters and which many groups now try to do in one or two play sessions of approximately three hours each.
} 
Another method that I have heard spoken of during networking periods at games studies conferences is when the researcher records spoken audio notes of their game session while actually playing simultaneously. I attempted to do this for a few sessions, but found the split focus it required very difficult to maintain. More often than not, I ended up dead in the game, prompting guild mates to ask what was wrong with me on those days, as I was not performing to my usual level. Add to this the requirement to communicate with my play group verbally using Ventrilo Voice-over-IP technology and it made for a complex and difficult approach.

Ultimately, I ended up relying on the second approach. When something of particular note occurred in the gameworld, I would pause my playing for a few instances and take a screen snapshot of the environment. Using an electronic note-taking program that time and date stamps entries automatically, I made a note of the interesting event or comment, cut and pasting dialogue out of the chat channels where appropriate. When my play session was over, I inserted the screen snapshot of that event to act as a memory jog for later reflection and analysis and I elaborated on my observations. In hindsight, this was not the ideal method, particularly after a long session, as my memory occasionally failed me on the importance of a given screenshot. Often this was because at the point in the gameworld interaction where I took the screenshot, it was an inappropriate time to tab out of the gameworld to take notes, and later on, I was unable to recall why the screenshot was notable. Given these difficulties and the possible loss of ethnographic detail that probably ensued, I would do my research differently in the future. I would prefer to follow the first method noted above, the filmic approach, as this approach is used to great success and rigor by digital scholars that I admire. I would anticipate it enabling a richer ethnographic account of gameworld activity, allowing a more nuanced analysis. 


\section{Qualitative Content Reference}

As a secondary method for my work, I perused game-related websites, blogs and forums and I consulted media reviews and commentaries on gaming as an activity. This approach to understanding the larger debates and understandings about the gameworld is common to digital worlds and game studies research. Silverman (2006, p. 48) refers to this ensemble of reporting, discussion and analysis as the "meta-game" and Taylor (2006) notes that a consideration of this meta-game or "distributed social sphere" (p. 57) to use her term, is essential to understanding gameworld life.

For my purposes, I used this meta-game content as a way of investigating the amount of talk that occurs around my primary question about whether or not gameworld participation is a contested activity, I felt it would be prudent to see what kind of talk occurs in the larger context, outside the game world specifically. At this stage in my research career, I did not attempt to use formal and rigorous discourse analysis techniques or world-wide web intertextuality approaches. My consideration of this content was illustrative and exploratory generally. Thus, following Silverman, I call my own use of this kind of content an informal content reference.

\section{Ethics \& Risk Management}

In summing up the issues of ethics and its wide and varied tradition, Ess (2008) notes that most Western ethics nonetheless have a shared intellectual tradition that rests on shared assumptions, "first of all, regarding the nature and reality of the individual and related assumptions about the relative role and importance of the community and other forms of relationship to the identity and function of the individual" (p. 7). Ess notes that every attempt to create an ethical system to guide conduct must rest on shared values and it is these values that 
form the ethos that guides that conduct, even while the content of the ethos may vary from group to group.

Digital ethics adds a further layer to this. Not only does the content and concern in digital ethics vary from group to group, a large number of the shared values differ. Central to concerns about ethics around social worlds are issues of respect for both digital and biological being. Within this comes issues of privacy and alienation (Bakardjieva \& Feenburg, 2000; Mckee \& Porter, 2009), of appropriate age of consent, and of who can be seen to be an informant in the study.

These were the issues I was faced with when I started my fieldwork and they guided my decision to work within a fairly pure participant observation mode, fleshed out by considering content from the meta-gameworld on the Internet. When devising a research approach, I abided by the guidelines of the Association of Internet Researchers (AoIR), the leading research association for digital studies, ${ }^{18}$ along with my sociological training in research ethics, and I considered the ethical issues online gameworlds present to researchers, as noted by Mckee \& Porter (2009). Because this project is driven by an ethnographic approach within a public gameworld, no direct questioning, surveying, interviewing, or focus groups were done. Following the direct observational style of a pure ethnography, there is no formal consent process required of gameworld inhabitants. The observations for this ethnography have been collected within a world in which inhabitants are aware that they are constantly watched. All

\footnotetext{
${ }^{18}$ In AoIR's words, the "Ethics Working Group, as composed of ethicists and researchers from 11 different countries, has produced a major report to assist researchers in making ethical decisions in their research. The ethics committee document on Internet research ethics was unanimously approved by voting members on November 27, 2002" as noted at http://aoir.org/?page_id $=54$
} 
observations were done within the public context of the gameworld, in a social context that inhabitants understand to be public, observable and recordable (Bakardjieva \& Feenburg, 2000). Gameworld inhabitants are aware that their actions are constantly monitored and recorded. As such there is no need for consent, nor for any option for self-exclusion of a specific inhabitant. All gameworld knowledge emerged out of my insertion and participation in the WoW gameworld.

From a research standpoint, the contact with inhabitants was passive. Following Herring (1996), I adopted a naturalistic research approach, in which I endeavoured to have my research intrude as little as possible into the normal everyday flow of the WoW gameworld. There were no discussions about the research in the gameworld. There were no interviews. The other gameworld inhabitants were not test participants and there was no interaction with the gameworld inhabitants within the social gameworld field which would take them outside their normal activities in the gameworld.

In keeping with my naturalistic research stance, and in order to minimize the researcher effects on the gameworld environment, I took precautions to not out myself as a researcher within the various gameworld groups in which I interacted as a participant. While this could be seen as a kind of deception, this is an approach that is common to ethnography. Indeed, there is a longstanding argument that could be made that all ethnography involves deception. At the same time, within the circles that use ethnography the most (primarily anthropology and sociology), it is commonly considered impossible to alert all potential participants to the presence of a researcher. Indeed, it can also be detrimental to do so, because awareness of a researcher's presence can and often does alter the behaviour of the participants (Berg, 2004; Davies, 1999; 
Denzin, 2004; Frankel \& Siang, 1999; Herring, 1996; Paccagnella, 1997). Therefore, while this researcher deception is considered to be an appropriate and necessary research tool, I undertook it with an attention to the risks involved, and I took care to ensure that these risks were articulated and appropriately managed.

Given that the nature of my project was to discover and document possible connections between participation in the World of Warcraft MMOG gameworld and the dominant views of leisure in the current western neoliberal context, I find no dimension of this project which can be reasonably anticipated to cause embarrassment, stress or other emotional, mental or personal discomfort or risk. Following classical ethnography, this is an observational project. When I detail specific interactions in this thesis, the inhabitants' identities are made anonymous. No attribution is given to reported words or actions. Per the approach used often in the social sciences (Berg, 2004; Gibbons, 1975; Paccagnella, 1997), generic neutral pseudonyms are employed (e.g. inhabitant A, inhabitant B, etc.) rather than the character names, in a further demonstration of my respect for the social reality of digitality within the WoW gameworld.

For this project, therefore, risks are manageable via a conscious strategy of nonattribution and anonymity, along with a deliberate strategy of not collecting personal or sensitive information from gameworld inhabitants. The gameworld inhabitants are therefore protected in a manner consistent with ethnographies within sociology and anthropology over the past century.

A concern for the protection of an individual's privacy in digital realms (Mckee \& Porter, 2009 ) is another value that is reasonably universal in ethics, in any realm of being. Privacy in a digital context is a messy issue. While email tends to be viewed in a straightforward manner as just one more form of personal communication, akin to paper letters and correspondence, 
opinions vary as to the public-versus-private aspects of various digital spaces, such as forums, blog comments, chat rooms and announcements on guild websites. In considering this issue as it relates to my own work, I have chosen to follow the path set out by other digital ethicists and scholars (Allen, 1996; Frankel \& Siang, 1999; Mckee \& Porter, 2009; Paccagnella, 1997; Robson \& Robson, 1999; Silverman, 2006; Sudweeks \& Rafaeli, 1996). I have treated the WoW gameworld as a public space generally and I have treated all of the Internet's metagame content as public spaces, where all discussions are part of the public discourse. Equally, any comments made in open chat channels in WoW, such as Trade, General and Defense, are treated as public. This means that no consent is required to capture and disseminate those public utterances in my work. Where it is necessary for the sake of clarity in this thesis work to refer to overheard utterance or interactions with specific individuals, no names are used. Instead, a simple lettering reference is randomly given to the example dialogue, so as to preserve the non-attribution approach and inhabitant's anonymity.

This research approach, ethics overview and risk management strategy was submitted for ethics review by Carleton University's ethics review board and it received final approval in November of 2009.

\section{Ethnography \& Analysis}

"Free time is tending towards its own opposite and is becoming a parody of itself" (Adorno, 2002, p. 188)

While I have been part of various gameworlds for more than three years now, the fieldwork portion of this thesis project involved participating in the WoW gameworld over a one year and three month span. My participation in WoW was started specifically for research 
reasons, and has since branched out beyond that narrow focus. While I have been part of the WoW gameworld, I have also been observing and reflecting simultaneously on my gaming and on people's reactions to my gaming. With the focus here squarely on the one and a half years that the World of Warcraft gameworld has been the centre of my gaming life, the understandings I formed seemed to follow along with the birth and growth (and many deaths!) of my WoW gameworld self across my multiple characters. I am mindful, too, of the fact that my avatars are part of me and part of my gameworld, as well as part of the worlds of several other players. Thus, the assemblage I am detailing here is constructed via the actions and vectors of my characters and those of others, as well as the built environment that is the WoW gameworld, the meta gameworld that surrounds WoW on the Internet and the various people I have met and spoken with outside of the gameworld who may or may not participate in online gaming. In order to understand the perspective I am building and bring that assemblage into focus, I must detail different interactions, and so a variety of stories must be told. Those stories are of character creation, of group interactions, of guilds and of attitudes.

Consequently, following digital studies scholar T. L. Taylor's (2006) approach to ethnography and style of analysis and being mindful of my attempt to operationalize my ANT perspective, I will present here a reflexive ethnography of my gameworld participation, as seen primarily through my two main characters, a Night Elf hunter named Taryelle and a Draenei mage named Taryas. ${ }^{19}$ The intent of this approach is to articulate the ways in which the WoW gameworld is structured by neoliberal principles and to use this articulation to argue against the

\footnotetext{
${ }^{19}$ With the exception of the names of my own characters, all names here, whether digital or not, avatar or guild, have been anonymized to protect inhabitant's privacy and adhere to university ethics requirements, though the character details have been preserved for accuracy and richness.
} 
faulty logic inherent in everyday assumptions of what MMOGs and their inhabitants are and do. In the process, I will problematize the question of the supposed freedom of leisure and I will demonstrate that in the context of WoW's digitality, the activities within which I engaged and observed in others was not 'free time', 'inconsequential', nor separable really in any way from notions of labour and neoliberal being. I will present and discuss how I encountered ontological errors in everyday and popular understandings of the digitality of WoW. In order to make sense of what this gaming thing is as an activity and a way of being, I will present my ethnography in a format that weaves together stories, reflexivity and analysis.

\section{Becoming a WoW Inhabitant}

On April 23 of 2008, I logged into the WoW gameworld for the first time. After randomly choosing a player-versus-environment realm, I perused the character creation options and decided to create a Night Elf Hunter, whom I named Taryelle. Playing alongside my partner's Night Elf Druid 'D', I figured out how to move my character around the landscape. I learned early on in this period that when a Night Elf jumped, she would often execute an energetic in-air somersault instead of just a hop, so those first few weeks found me often jumping around just to see her tumble gracefully in the air. I also learned the myriad ways of shooting my bow, and I figured out how to use my pet to help me kill enemies or do "crowd control', which is the management of more than one enemy's attention at a time. I figured out how to loot the enemies' bodies and how to sell the unwanted items to NPCs or at the auction house to other players. I learned the difference between the two additional ways to earn gold via gathering and crafting. I chose the marksmanship talent specialization from one of the three talent trees offered to every player as based on their class, and I diligently read up on the merits 
of each skillpoint in order to try to pick the best skill mix, but ultimately I often picked talents based on a mixture of instinct and the tool tip information. In effect, I spent that first month and the first 25 levels of my character's life learning WoW's customs, expectations and idiosyncrasies, and my place within them. In the WoW gameworld, the first 20 levels or so of your character's life are a prolonged training period, disguised as play and interaction, and rife with choice and possibilities. The quests and tasks in those first levels teach inhabitants the desirable gameworld conventions, folkways, and habits. This is perhaps the genius of the WoW gameworld design: it is able to take training and tutorials and memorization and turn it all into a package that is engrossing and does not feel tedious. This aspect of the gameworld is one I would come to encounter over and over in varying degrees throughout my WoW career.

\section{Learning and Levelling}

Both the initial character creation process and the subsequent initial levelling process act as a kind of socialization action field, training the inhabitant to accept the in-built limitations and constraints of the gameworld and its potentialities for actions. Akin to what happens in nongameworld, those first few months were a long series of exercises in constraining expectations and tutoring me in the actualities of the gameworld. While I might have liked to inhabit a character that uses a bow, wears plate armour and can cast spells that allow me to fly, the process of making Taryelle was a process of accepting compromise and understanding constraint. For Taryelle, if she wanted to be able to use a bow, she had to give up on the idea of being able to cast spells, and the only way she was going to be able to fly was to reach level 60 and buy a flying mount. The bird form that was part of the druid class would forever be closed to her as a hunter. This was also so in the crafting system. While Taryelle might have enjoyed being able to 
make her own bows, along with her own leather and mail armour, that option was only available to the weaponsmith and was not possible at all in Taryelle's own leatherworking-skinning crafting career. Thus, character creation, the initial levelling process and the crafting career choices all act as indoctrination fields into the specific ethos of capitalist power relations and modes of production within the WoW gameworld, a point I will revisit later.

While not actually matching the "be all that you want to and can be" mentality that is often found in advertisements for MMOGs or even in the inhabitants' own discussions of why gameworld participation is attractive, that is not to say that time spent in WoW was not engrossing and did not enable that mentality in a reduced form. Looking back on my notes from those early days, I realize that I was playing six to eight hours a day. Saying it that way sounds so bald and makes that play time seem so strange in hindsight. At the time, I was feeling wonderfully immersed in a fantastic new world, full of things to see and do, things to learn, with skills to master and people to meet. The possibilities for existence within WoW seemed vast, and the constraints that I was being trained to accept about WoW, both via the gameworld's own mechanics and most often via the expectation and experiences of other more accomplished players, frequently went unnoticed by me in the joys of exploration, level attainment, crafting, character development and sociality. Time flowed swiftly and easily, and in more than a few of my field notes, I remarked that it seemed I had just eaten lunch only to look up at the clock in the kitchen and note that it was time to start thinking about preparing dinner.

I noted feelings of joy and frustration, the uncertainty of knowing if I was good enough at my hunter role, the thrill of the boss kill and the fun of satisfying curiosity by roaming around the vast landscapes. WoW is a large gameworld, relative to others, and there are a plethora of 
regions or "zones" to be discovered and experienced. Certainly, at level 25, I was restricted on where I could explore safely, but as I progressed, found and joined a guild, and levelled, I learned. Around level 32 I started getting curious about other classes. Given that I had made an agreement with my partner to only play Taryelle with him so that we would go through the levels simultaneously, ${ }^{20}$ this curiosity meant I had to create a secondary or alternative character, and this alt could then be one that I would be able to play in my own time without the requirement to play with $\mathrm{D}$. This is how Taryas, a Draenei mage, came to be.

What I also started to notice around the time I hit level 45 on Taryelle was how people started reacting to me when I told them that I played WoW. Often the conversation went along the same lines as one I had with one of my bookstore coworkers, recorded shortly thereafter as the following paraphrase in one of my research notebooks:

Coworker: What did you do last night?

Me: Oh we hung out at home, ordered in pizza and played WoW.

$<$ silence.... stares.....

Coworker: All night?

Me: Well, we did sleep eventually, but yeah. The instance took awhile.

$<$ more blinking and staring $>$

\footnotetext{
${ }^{20}$ This agreement was one he and I had carried over from our LoTRO experience and it is one we made for both social and functional reasons. D. and I wanted to keep doing the same quests together (even those technically considered soloable) and we wanted to be able to do the same instances together, such as Stockades or Scarlet Temple. It made the non-questing time more fun as well, because we could both visit a trainer or browse the auction house at the same time, comparing what was new and what we planned to buy. Also, we had discovered in LoTRO that we worked very well as a dyadic team, and that social aspect of the gameworld was one that was fulfilling and enjoyable for us.
} 
Coworker: You play games? Really?

Me: Yeah. Why?

Coworker: Well I suppose there have to be a few people who play those things who are actually fairly normal.

While this is but one snippet of conversation, I have encountered this attitude and similar ones repeatedly when I tell people that I participate in WoW. Around month three of my WoW life, I started to perceive that my gameworld participation was not considered normal or acceptable by many. Along with the theme of normalcy and social acceptability that cropped up in these conversations, other themes I encountered in conversations included quick relations of gaming to addiction, to relationship breakdowns and other social ills, as well as a general but usually not fully articulated notion of gaming as a waste of time. ${ }^{21}$

But the talk was not always negative. I sometimes found good surprises, as was the case at a business social event for my partner's office. After the meal and a few desserts, we ended up randomly sitting down next to one female-male couple and somehow the conversation turned to gaming. As it turned out, both of the individuals in the couple played WoW and had since the gameworld's launch in 2004. They both played warriors: She is 'F', a human fury warrior (DPS) and he is ' $\mathrm{M}$ ', a dwarf protection warrior or 'tank'. As I have since discovered, it is often the case that when casual social talk between erstwhile strangers turns to a discussion of a mutual MMOGs and to play experience, the talk centres at first on servers, guilds, classes and gripes.

\footnotetext{
${ }^{21}$ Game as a waste of time was a common theme I kept encountering, and it was often coupled to the idea that this was doubly true for women. Why would a woman game? Of course, what was the viable or acceptable alternative to time spent in the gameworld? This alternative was never voiced or offered up to me by others.
} 
That evening was no different. We found out we played on different servers, but all four of us played Alliance characters. We chatted about our server and our guild, comparing notes on lag and guild politics. D and I talked about our characters, comparing them to what we knew of Lord of the Rings Online (LoTRO), another MMOG we had played extensively for six months and had recently abandoned. We noted in particular how huge the WoW gameworld felt to us, and how exciting it was to run around in something that was so large, comparatively speaking, to LoTRO. M. spoke little overall, with his conversation leaning towards questions about our time in LoTRO versus WoW, and some light commentary on how the game had changed over the year. F. made up for his comparative silence with a long, colourful and animated discussion of her time in WoW. Her conversation ranged from people's reactions to her as a player, as a female playing a melee plate-wearing DPS character and as a DPS warrior, from a time when most warriors were automatically tanks. She came back often to this latter theme, and it was an obvious point of pride for her that her fury warrior talent build and playing style were considered weird, and that she was shunned by PUGs at first, but then often copied, once other players in and out of her guild noticed how high her DPS was on the instance damage tallies. She weighed in on the merits of other classes and chanced a few opinions of what kind of people played what classes. I often heard her exclaim what was an obviously favourite saying, that "people who play palys as mains are CRAAAAZY!" ${ }^{22}$ I found her and her partner highly entertaining and informative, and as deeply vested in their WoW digitality as they were, I sensed that this chance meeting would be a turning point.

\footnotetext{
22 "Paly" is the common short-form for a paladin. The paladin is a jack of all trades class, a plate-wearing hybrid that can be tank, healer or DPS. depending on how the player talents and gears themselves. In Guild A, palys are most often healers, as is the case of Guild A's guildmaster.
} 


\section{Finding a Guild}

I was right. Prior to that evening, my gameworld experiences had been primarily either part of the dyad that was my partner and I playing together, or solo, a fact that reflected itself in highly descriptive but rather superficial field notes. But, as a result of that evening, D. and I transferred our level 50 selves over to F. and M.'s realm, and joined their social guild, Guild A. ${ }^{23}$ Overnight, D. and I went from a small isolated dyad of hunter-druid, where we were forced to join in pickup groups ("pugs") for most of the group content and we bought most of our gear, over to a large, noisy, very friendly and talkative group of long-time players and Guild A guildmates. With F. and M. acting as my primary field stars, per Berg's (2004) take on this, ${ }^{24}$ and backed up by the very loquacious unprompted commentaries on the environment by my new guildmates in Guild A, my insight into the WoW gameworld intensified and deepened.

Suddenly, I could be social and play and craft and get supported by people who had a similar take on the gameworld specifically, and on digitality more generally. Fun, social, dedicated, often silly - these were the new hallmarks of life on the new realm with the new guild. Prices at the auction house notwithstanding, the biggest difference between life on the old and new realms was definitely the guild, in which both F. and M. were obvious insiders. Most of the guild had been part of WoW long enough that they often could and would wax nostalgic about

\footnotetext{
${ }^{23}$ Guilds can be roughly divided into four types. There is the social guild, where the only requirements are to be courteous, friendly and helpful towards your guildmates. There is the levelling guild, which is similar to the social guild, but adds the requirement to help guildmates with the process of levelling their toons to the level-cap (doing group quests and instance runs with them). There is the casual raiding guild, where the focus is on doing the large-group end-game instances together as a guild, but without the requirement to be present for every raid; whereas in the fourth type, the serious raiding guild, that requirement is a hard reality. Failure to attend raids or perform one's role in the raid or guild as required can result in expulsion from the guild.

${ }^{24}$ Berg says of fieldwork stars that they "may hold the key to deeper penetration into the lives and perceptions of inhabitants in that setting" (p. 172). Certainly, this ended up being the case for me with F. and M.
} 
the good old days of Molten Core raids and level 60 'uberness', and they were set well enough in the game in material means that they could afford to give us things that made our gameworld life easier. From level 50 to level 70, I rarely had to do instances with people who were not in Guild A, and there were always people available to help. Whereas before I had had only D. and the gameworld, now I had both of us, but also a home and colleagues. I also had a new way to learn about the norms of the gameworld, and about the ways in which inhabitants talked about themselves and their gameworld activity.

\section{$\operatorname{Re} /$ Actions}

As I continued to level both Taryelle and Taryas, and my participation in WoW permeated my daily life more deeply, I found myself having to grapple with how to deal with the time demands of my gameworld activities, both social and functional. I have several friends who do not participate in gameworlds. Speaking of my gameworld participation to them found them either changing the subject as fast as possible, or sighing and staring off into space. I could talk about a whole host of other digital activities that I engaged in, from blogging to Facebook to Guitar Hero, and they would listen and talk about it with me. I could talk to them about my school pursuits or my budding relationship with my in-laws and while none of them are students or engaged or married, they would listen attentively and ask questions and stay engaged. But talk about gameworlds? Tell them about something that had happened to me in WoW? Bad idea.

I quickly got a sense that it was something about the general social conception of gameworlds that they were not comfortable with. And this was only conversation. When I moved my mage alt to hardcore and hybrid raiding guilds for two months in order to see what gameworld life was like on the other end of the guild life spectrum, I had to make time in my life 
to accommodate the nightly mandatory raiding. This is when the displeasure and misunderstanding became evermore obvious. I quickly discovered that telling non-gameworld friends that I had to be home at 9:30 PM for a raid got me strange stares and sighs, at best, and outright hostility at worst. Occasionally, I found myself deliberately donning my student researcher hat to them in order explain the obligation. This made it easier for my non-gameworld friends to accept my raiding activity, but it was still met with an attitude of beleaguered tolerance. ${ }^{25}$ More than a few times, I simply claimed another obligation entirely, in order to be able to make it home on time without the mixed bag reaction.

This got me reflecting on the large variety of activities that might have been accepted unquestioned and on the feelings I was experiencing towards my cadre of friends. I have an active life, generally. In addition to my gameworld activity, my studies, and my paid work at the university and at a bookstore, my leisure life involves reading for pleasure and for the social involvement at my bookclub, cooking, cycling, volunteering at a military family centre, frequent gym time and a lot of travel to various friends and family across Ontario and Quebec. In thinking about the gaming aspect of my life, then, I realized that the only part of my regular leisure activities that could possibly be deemed dedicated and involved enough to be considered a hobby or a leisure career was my gameworld participation. ${ }^{26}$ The same seemed to be true of a variety of other people I met in WoW. For them, WoW was an important part of a full life. The anecdotal evidence from my interactions with others found a number of married couples who

\footnotetext{
${ }^{25}$ I have been unable to find methods research on the management of the hybrid researcher-gamer status, or on the reactions to and management of that status. This lack of literature and work is surprising and warrants possible future investigation.

${ }^{26}$ The fact that my gameworld involvement started out as a research environment but then morphed into both research and a hobby that I enjoyed is a topic that would be interesting to play with in a paper on the work/play divide in games studies.
} 
played together, ${ }^{27}$ and a large smattering of professionals, academics, women and seniors. ${ }^{28}$ In

short, I met very few people who might be said to embody the prevailing stereotype of the online gameworld inhabitant.

In thinking this through, and in letting my imagination roamed around an imaginary map of possible hobbies and activities, from going to the gym to making a scrapbook to playing on a bowling team, I realized that the strange package of feelings I was feeling as it related others' reactions to my gameworld participation were a mixture of resentment, belligerence and shame. The first two were not surprising to me. After all, here I was, feeling as if I had to constantly justify my gameworld time to my non-gameworld friends. But the shame? It was not as if I was heading home to shoot up illegal drugs, watch pornography or do any other of a number of illicit activities. Yet there I was, an adult, feeling shameful about my desire to engage in an activity that I subscribed to and paid for and that that I enjoyed, ${ }^{29}$ all which took place within the context of a digital world in which I had made some new concrete friendships that seemed likely to bridge over into the non-gameworld.

\footnotetext{
${ }^{27}$ This phenomenon of couples who game together was the subject of an interesting qualitative study on the social capital between gaming couples by Bergstrom (2009), and it is an under-researched area of game studies.

${ }^{28}$ My experience is borne out by statistical demographic data from both o data from Blizzard (2008) and the Entertainment Software Association (2009), who both find that more seniors and women play MMOGs such as WoW, then do adolescents or children.

${ }^{29}$ I have met other researchers who have encountered this stereotype and these feelings and reactions, both in their research participants and in reactions to their own game participation. It is often a topic of conversation during discussion and breakout sessions at academic conferences whenever a group of games studies researchers gather in panel and paper sessions, particularly within the annual conferences for the Association of Internet Researchers and the Canadian Games Studies Association. Yet, despite this widespread shared situation, I have been unable to find anything published on this as a specific and dedicated topic. The closest I have come to being able to corroborate these feelings and reactions via literature are hints and allusions in Taylor (2006) (such as the one quoted at the beginning of this thesis), Consalvo (2007), Bergstrom (2009) and a few scattered discussions and anecdotes, such as those published herein as Appendix II. This curious lack drove some of the questioning therefore in this thesis and I plan to further investigate it more concretely in my PhD studies.
} 
The point to this? When Taryas was reaching level 72 post-Wrath of the Lich King expansion, I was learning to hide the fact that I was involved in WoW from my friends who were not. Increasingly, I came to accept (somewhat reluctantly) the knowledge that, if I got excited about something I had figured out in the gameworld, or about an accomplishment I had attained, the only people I could share it with were people like D., F. and M., and others who also were part of WoW life.

\section{'Us" vs. "Them"}

This "us against them" was one key driving factors behind this thesis' exploration of what WoW is relative to general reactions to WoW digitality. This besieged mentality was subtly reinforced with every negative reaction I encountered to talk of my gaming activity to nongaming people. This seems to be common among WoW inhabitants. Certainly, various people in my guild remarked upon it at various times. $M$ calls it the 'ugh' reaction, because he has encountered it often, with people saying to him:

Person: "you're not one of them are you?"

M.: "One of what?"

Person: "One of those computer geeky losers!"

When recounting this unprompted story to the guild in guild chat, M.'s response when others questioned him on his feeling about it was to say:

"So why does it even surprise you that I don't tell most people that I game? I am not a loser, I am normal, I want to be seen as such. WoW shouldn't change that for people, but 
it does. If I play WoW, I'm a loser. So I don't tell them about it, unless I know they are in WoW too".

This phenomenon, of feeling closely connected to these fellow gameworld people in a kind of "Us against them" mentality, is one that F. referred to one night as "the portability of friends". In her words, it made being a military spouse and moving across the country all the time easier to deal with, because "we packed all our friends in a little computer box and just took them with us". At the same time, it also created some strange and tense scenarios when the gameworld friendships spilled over into non-gameworld situations.

Via gameworld chat one evening, M. told a story of going with F. to visit some guildmates in Buffalo, NY and getting suspicious treatment by US customs officers about the fact that they were visiting gameworld people that they otherwise had not met before. His reaction to the search and delay at the border was recorded as:

"They didn't want to let us through. We were strange, cause we hadn't seen them [the guildmates] for real yet before that, but it seemed to be more the WoW thing than the online thing, I think. I wanted to figure him out. I wanted to say to him, 'Yeah, but headin' down to a golf tournament to play a game with a bunch o' strangers, where you hit a ball with a stick around really fake green grass for a weekend, then get drunk... that would have been just fine, apparently. I wanted to ask him... why is gaming so strange? You Americans like to watch people spend an entire day making left turns at really high 
speeds on smelly black stuff. But that's totally cool! So why not WoW? At least I have friends from it." 30

In keeping with my researcher stance on my gameworld participation, I wanted to try to understand why the other people in my life, outside of WoW, saw my WoW experiences as not something to be talked about. One evening, 'J.', a close, non-gaming friend, asked me out for coffee and I declined, noting that Taryelle was scheduled for a Guild A nostalgia raid of Ahn'Qirag an hour later. A long silence ensued. I suspected it was because I had also been spending a lot of evening time raiding since Taryas joined Guild B, a raiding guild and I wondered if that was behind her reaction. Given that her live-in boyfriend "A." participates in WoW, I wondered what about what it was about my gaming that $\mathbf{J}$ found so strange. While I thought I knew what kind of response I would get, I was unprepared for the reality of that Facebook chat-based conversation.

$\mathrm{J}$ : So you're turning down real friend time to play a game? And you don't see what is wrong with that?

Me: I went out with you yesterday. Tonight, I'm doing an activity with a bunch of friends. Does it matter that it is in WoW?

$\mathrm{J}:$ Yeah it matters.

Me: Why?

\footnotetext{
${ }^{30} \mathrm{M}$. is referring to NASCAR racing.
} 
J: Cause they not real. And you're getting addicted.

Me: <quiet a moment> .... Real friends? Or real people?

J: Both. You have no idea who they are. They're not real. And you are wasting way too much time doin' that stupid game.

Me: Do you feel this way about A. 's playing WoW?

$\mathrm{J}$ : Yeah yeah I know A. plays but not like you do, and besides he's a guy. They're supposed to do stupid things like games. Whatever. Call u later. ${ }^{31}$

What seems so significant about this small conversation with one of my friends is that it seems to encapsulate the entire package of assumptions, suspicions, misconceptions and circulating stereotypes about online gameworlds and participation within them, and about the apparent type of people who are participants within them. Is gender involved here? The fact that I am female and yet committed to this time-intensive gameworld? Possibly. Certainly J. hints that my femininity is part of the issue. I am not a gender studies scholar and am only lightly versed in the literature. As such, I do not feel qualified to hazard more than an instinctive reaction to hers. It is my belief that this would be a bit more socially acceptable if I were male, talking to male friends.

Gender aside, it still felt like a contradiction. A fellow student colleague tried to puzzle this out with me one night in the pub, and not knowing the truth of my biological age, assumed it was an age/digital divide issue. He knew my actual chronological age and assumed my friends

\footnotetext{
${ }^{31}$ The irony behind this conversation? It occurred in Facebook chat.
} 
were in the same older section of generation $\mathrm{X}$. What he did not know is that my non-gaming friends are actually all part of the first wave of the supposed digital generation. Most of them are in their mid-20s, unmarried, with no children. They are comfortable with technology, with all of them maintaining active Facebook networks and playing some forms of video games. ${ }^{32}$ So why was WoW not part of this socially acceptable package of digital pursuits? What is it about MMOG participation that made it so socially suspect?

As I started researching this question, I started paying more attention to the way WoW inhabitants spoke about their gaming, and that of others, in-world in the public chat channels and on the large fan-sites and group blogs. The frequent posturing and flaming aside, most people seemed to take a stance towards their own gameworld participation in opposition to or against an apparently dominant view of MMOG participation as an unacceptable thing for an adult to do. This unacceptable notion seemed to be framed via what Taylor (2006) notes is some sort of mythical folk devil of the gamer as an anti-social unwashed adult who refuses to leave childish things aside and lives online in a world of dragons and fairies, demons and demi-gods, because he is capable there and it lets him compensate for a lack of social skills in his 'real' life. Note that the choice of the male gender in this stereotype is deliberate, because I found that accompanying these sorts of comments was often the pervasive view that women (girls, as we are most often called) do not game, despite statistics to the contrary. ${ }^{33}$

\footnotetext{
${ }^{32}$ Facebook games such as Bejewelled and Scrabble, along with console games such as Wii Fit, Guitar Hero and Rock Band are the most popular among my friendship web of non-gameworld people.

${ }^{33}$ This view of "girls don't game" persists, despite statistical evidence and my own lived experience. The game industry's professional association, the Entertainment Software Association, has done extensive statistical modelling on the gaming industry. In their most recent report, they note that "forty percent of all game players are women. In fact, women over the age of 18 represent a significantly greater portion of the game-playing population ( 34 percent) than boys age 17 or younger (18
} 
What is operating here? The attitudes I encountered towards online gaming as an activity, despite it being an undertaking pursued in an actor's free time for the purposes of fun, friendship, challenge and reward, must be probed in order to sketch out possible associations between the attitudes and the activities. What emerged for me as I immersed myself in the WoW gameworld was that there is a definite disconnect between the general view of what leisure activities are supposed to be and do, and what they often are and give to the individual. In order to negotiate an understanding of these associations here, I need to delve into a host of binary approaches and tease out the more subtle potential associations.

\section{Neoliberalism, Leisure/Labour \& WoW}

Online gaming has become a global leisure possibility. Online gaming as an environment and as a leisure activity is embedded within a neoliberal socio-political framework that is reflects its modes of governmental behaviour. When the group of leisure qualities I just detailed is matched up against the highly rational, deeply consumerist and intensely individual ethos that characterizes the Western neoliberal context, and compared to my experiences and observations in WoW, I find a strong number of associations and connections.

In the literature review section of this work, I have defined leisure and labour from various sociological stances. Outside of the scope of those debates, and outside of the academic debates of whether or not either are useful analytical concepts, I have found that the common, everyday notions of what leisure and labour are stubbornly persist. In very simplistic terms, it is generally understood that labour is paid obligatory work, whereas leisure is unpaid chosen fun. 
In the everyday sense, leisure and labour are ways in which an individual's time is used, which fulfill economic or social needs and which express an aspect of an individual's unique personality. Additionally, there is a hierarchy of valuation on what the most desirable types are for each realm of human activity. For the realm of work, the most desirable types of activity lay in the professional, knowledge-oriented occupations (Beatty \& Torbert, 2003). For the realm of leisure, the most desirable activities involve the exertion of the body for health (Crawford, 2005; Featherstone, 1982; Iso-Ahola \& Mannell, 2004; Iwaski \& Mannell, 2000; Turner, 1996;), the exertion of the mind for self-expansion (Beatty \& Torbert, 2003; Bryce, 2001; Iso-Ahola \& Mannell, 2004; Iso-Ahola, 1997); with a possible third addition of activities that explicitly involve and strengthen social ties of both family and friends (Beatty \& Torbert, 2003; Iwaski \& Mannell, 2000; Kelly, 1978, 1999; Neumeyer \& Neumeyer, 1958; Rojek, 1989).

The point here is not to answer a question of why gaming as an activity is attractive to the gameworld participant yet unattractive to the larger social sphere of people. Indeed, the ethnographic approach I have followed for my project would make attempting an answer to that kind of question unwise. Instead, I would like to suggest ways in which is it curious that it is not seen as attractive in the more general everyday sense, given what occurs in the gameworld. To do this, I will discuss the highly rationalized consumer life that is the standard in the North American context. I will then discuss the highly rationalized consumerized life of the WoW gameworld. Via the drawing of comparisons and commonalties, I intend to show how similar the two actually are, thereby making strange the commonsense idea of gameworld life as unacceptable or suspect. 
Rojek points out (1993, p. 97), everyday life has been "wedded to a rational view of work and leisure". This rationalized life carries with it an almost Calvinist stance. Pleasure in activity is acceptable, so long as the activity is functionally appropriate to an individual's life, status and age. Of course, what is functionally appropriate is determined by a neoliberal capitalist ethic of calculation and justification. Rojek notes that ideas of appropriate leisure under capitalism have been shaped over time via civilizing processes of the desirability of certain activities against determined goals. This leisure consciousness is comprised of those activities, processes and goals deemed acceptable and worthy of the bourgeois lifestyle. Each of them are therefore formed and shaped within a neoliberal capitalist framework. The goals might be individual, but they can equally be structural. Ultimately, each goal is subject to a cost-benefit analysis, and their desirability and acceptability is determined according to the results of that analysis. Leisure must then be able to be restorative to an individual's ability to labour, and should never mimic labour.

If work is accepted be as defined herein, as something that is innately human, something that is creative, productive, expressive and necessary, then why is it that leisure, supposed to be exactly the opposite of this, more closely mirrors this definition of labour than most paid labour does? And what happens when that rewarding, creative, fulfilling leisure that expresses one's sense of humanity occurs within a deliberately constructed and seemingly unnatural digital world? Is this dichotomy part of the answer for the confusion around what gameworld participation is, and for why it is a contested leisure activity?

Based on what I have experienced in WoW, this muddling may indeed be part of the issue. Certainly, as it relates to digitality generally, and online gameworlds specifically, part of the lack of acceptance stems from the mystique and perceived opacity that accompanies digital 
technology. Law (2003, p. 4) argues that all the agents and particularities and subjectivities that make up the messy realm of an assemblage tend to get melted or dissolved into the logic of the system into which they are inserted. I argue that this is what happens with the commonplace understanding of the online gameworld inhabitant. All the particularities of each individual, their toon, their guild, their life and its context gets filtered through the neoliberal logics I have discussed here, strained through the dominant discursive frame of the folk devil/hacker, and reduced to a picture that is often alarmingly inaccurate. This picture, or knowledge architecture, produces a sociotechnical context or geography, then, to use Law's terms, through which online gameworld participants are enabled or constrained in their presentations and others interpretations of their being.

In this sense, then, the gameworld inhabitant assemblage follows the cyborg notion from Haraway (1991, p. 150) :

"A cyborg is a cybernetic organism, a hybrid of machine and organism, a creature of social reality as well as a creature of fiction. Social reality is lived social relations, our most important political construction, a world-changing fiction...The cyborg is a condensed image of both imagination and material reality, the two joined centres structuring any possibility of historical transformation"

This notion of the gamer concept is a hybridic thing, an amalgam of the flesh and the machine, a melted messy unstable existence in both flesh and bytes, but Law would note in his discussions of hybridity, it is also as a performative hybrid, something has a reality and a possibility simultaneously. In Hayles (1999) terms, it is both pattern and presence, neither fixed, both 
processual, always in both states simultaneously. And given our inability to ever access a core and concrete "true" understanding of what an online gameworld inhabitant is, at its essence, due to the way in which our understandings are filtered into and through us, then the solidity of the concept disappears from possibilities and its traces get melted or merged into the traces of other aspects of human life, digital, non-digital, economic, neoliberal, whatever. From this melted and merged conceptual substance comes each gameworld inhabitant's understanding of their gameworld activity, merged as it is within the context of their life, their assemblage.

I find another challenge is to identify the ways in which economic roles found in any realms of life provides contexts, resources, limitations, and orientations for the rest of life-family and community as well as leisure. What are the structural possibilities and limits placed on all the dimensions of life not only by economic roles but also by the nature of the economic system itself? How are the conditions of leisure and all of ordinary life constructed within a socioeconomic context that shapes time, space, and energy as well as market power? The question is not the simple determination of life and leisure by work, but how determinative definitions of both the self and society are learned in a power-differentiated social context, within which market capitalism is but one facet (Rojek, 2004; Turner, 1996). These exist alongside an ethos of individuality and self-determination and a strong concern for social status along stratified lines.

Participation in MMOGs as a leisure activity can be a problem, then, when compared to Stebbins' definition of uncoerced leisure presented earlier. While MMOG engagement often appears to start out as a way to engage in un-coerced activities, the ways in which others within the game environment quickly assert a normative and prescriptive influence over how game time 
should be engaged in can put the lie to the idea of gameworld participation as being wholly uncoerced.

\section{Hardcore Guilds \& MMOG Labour}

Consider the requirements put out by many "hardcore" raiding guilds. These guilds require their members to participate in regularly scheduled and very frequent raids, occasionally even daily and it is this participation and role requirement, with no expectation of sociality, camaraderie, collaboration or "fun", which gives these guilds the self-determined moniker "hardcore". As experienced by me and also noted by Silverman (2006), hardcore guilds function as if there is no life outside of the gameworld. Between members, there is rarely any accommodation made to the demands of the so-called "real life" of the inhabitant. Within these guilds, members are not allowed to pause or leave a raid to take care of "real life" issues. The gameworld slang of "aggro" or aggravation as applied to "real life issues" is telling, in the ways it speaks of the predominance of importance to the gameworld over the non-gameworld. Whether it be "wife aggro", "baby aggro", "parent aggro", "health aggro" or any other demand that is not functional to the success of the raid group on any given day or evening, hardcore guild members are expected to keep the non-gameworld out of the guild and away from its activities and goals. Within such guilds, failure to participate or adhere to guild rules and requirements can come with a heavy price. Loss of guild membership is the obvious one, but also loss of status, coupled with a perception that the discredited guild member is not a serious player, and thus is a failure, a "waste of space", a "luser", a "kid" or a "woman".

As I will demonstrate in following discussion, raid-oriented hardcore guilds both reflect yet problematize the neoliberal values of human life within digitality. The theme within this 
story is one of obligation, of the consequences for non-conformity and a kind of digitality that is dressed up as 'fun' leisure. In order to better understand the ways in which different guild styles and cultures influence the way inhabitants talk about their gameworld participation and in order to understand the WoW gameworld ethos more generally, my mage Taryas joined two different hardcore guilds, Guild B and then later after expulsion, Guild C. Guild B was a guild geared at raiding difficult high end instances only, and defined itself as a hardcore raiding guild. Guild C defined itself as a hybrid raiding/social guild, with hardcore intentions.

Within Guild B, the only thing that mattered was gear. Raids were not engaged in for the purposes of fun, or to experience the entertainment of the high endgame content, or for the thrill of working alongside like-minded people in a successful group. Raids had one stated purpose only: obtain epic gear. ${ }^{34}$ Being in the guild meant complying with the requirement to show up to the regularly scheduled raids with all the required potions, food, and lack of the aforementioned distractions. The convention of this guild, and others like it, required members to maximize their characters' abilities and capabilities in each member's non-raid time, so that their raid participation would the best possible in their respective role. In this guild and others of its ilk, this optimization process plays out through several vectors. The obvious one is gear maximization, in which a whole host of possibilities exist, from maximizing faction reputations to ensuring access to the best gear buffs, to maxing out crafting skills such as enchanting and

\footnotetext{
34 While the gear-centrism of the raids was a raid's openly stated raison d'être, I noticed a secondary un-stated factor: Status. The more content Guild B was able to successfully run through on a guild-only raid, the more accomplished the guild could appear to the gameworld realm in which it operated, and ideally to the larger general context and community of the overall metagameworld of WoW. Aside from accomplishing realm firsts of downing specific bosses before anyone else, the ability to be seen has a truly hardcore guild requires these accomplishments to maintain stature and prestige, to recruit ever more accomplished inhabitants, and to apparently inspire fear in situations that required PvP. I find this status question interesting and compelling, and certainly worthy of future further dedicated study.
} 
jewelcrafting so that one's gear is constantly sporting the latest and greatest of enhancements, to ensuring one carries an entire extra bag of epic gear that allows one to switch roles in mid-raid if necessary. $^{35}$

There are others as well. These include but are not limited to: theory crafting and the use of theorycrafted talent builds; staying up to date on changes in strategies for the successful "downing" of instance bosses; and the constant re-engineering and tweaking of a toon's abilities.

If a member failed to constantly and consistently meet these requirements, or failed to perform their role at a level that the guild leaders found satisfactory, there was no discussion or options. One was simply expelled from the guild and blacklisted by its members. In my case, I lasted two weeks in Guild B before being expelled. A very brief private discussion with a guild officer yielded my three offenses. In the first, I had violated the anti-sociality "put up and shut up" approach to the hardcore guild, by daring to speak out in guild chat one night, to ask for assistance in finding a quest objective. Apparently, I had been expected to figure that out on my own, through web resources and other options, and not burden my guildmates with my ineptitude. Collaboration equals failure, in Guild B's mentality. A hardcore guild needs no sociality. Needing help from someone is equated to failing to be elite or "uber". Guild chat was supposed to stay quiet, except for raid time postings, heroic instance run openings, and other such opportunity-related interactions, all of which were supposed to be slanted towards gearing

35 Guild B had specific regulations for members who played the utility classes, such as druids and paladins. For raids, these utility members were required to carry along a full set of completely maximized epic gear that would allow them to play a secondary meta-role in a pinch. This requirement is interesting and contradictory, given that it undermined the hardcore raiding guild ethos, in which members are supposed to fully adopt one meta-role only (tanking/healing/DPS) and focus on it, to the exclusion of others. To my mind, it speaks to the intent of Guild B to be the best possible at absolutely every aspect of the gameworld, which included expecting its utility members to always be "full leet" (to use Guild B language), meaning to be able to fully play every single aspect of one's class, and thereby be part of a select elite group of inhabitants who are capable of excelling at everything. 
up and finishing raids. My second violation was that my mage had failed an optimization test the previous evening before a raid. She had a blue (superior) level gem in her helm, rather than the optimal purple (epic) level gem. In January 2009 when this happened, epic level gems were selling at the player-determined Auction House for anywhere between $1000 \mathrm{~g}-3000 \mathrm{~g}$ on my realm. These prices were grossly inflated relative to other realms, and my mage could not afford the gold to buy that gem, because she was still spending much of her gold to level up her enchanting and alchemy skills. None of this mattered. Using less than the best gear and enhancements was "epic phail" (sic) according to the guild officer with whom I spoke, making me a "luser" (sic). ${ }^{36}$ These two failures alone were sufficient to justify my expulsion, I was told. However had it not been for a third failure, they might have made a concession to me, given they had no other highly geared mages in the guild at the time. ${ }^{37}$ The final and worst of my failures? In the evening prior to my expulsion, I had not consistently output $3000 \mathrm{dps}$ in a fight with the boss Heigan the Plaguebringer in the $10 \operatorname{man}^{38}$ version of the Naxxramas raid instance.

The Heigan fight is notoriously difficult. It is done in two phases which cycle back and forth until Heigan is dead. The first cycle phase of the fight is straightforward for ranged DPS classes, such as my mage, and for healers. The ranged and healing group stand stationary on a raised platform at the apex of a triangular room and cast damage and healing spells or thwock

\footnotetext{
36 In a practice that dates back to text-based multi-user dungeons (MUDs), words are deliberately mis-spelled in the interests of turning them into game-specific jargon. "Phail" is one example of this. "Luser" is another, but has more layers of meaning to the spelling. A "luser" is someone who uses other people deliberately, unscrupulously and with great malice. Being called a "luser" is orders of magnitude more insulting to other inhabitants than being called a "loser". The latter is a simple putdown meant to imply that someone is dumb or does not "get it", whereas the former is more pejorative.
}

37 The WoTLK expansion had been out less than two months at the time, making it difficult for Guild B officers to recruit a full and "properly geared" roster of classes within the guild.

${ }^{38}$ The gendered term "man" here is lifted directly from WoW, where all groups are referred to by the number of people required to do them properly, but always by using the gendered term man. 
arrows at Heigan, while the tanks and melee zigzag Heigan back and forth in a coordinated fashion around the expanse of the room, all the while avoiding the instant death of Heigan's plague-filled green waves of poison which shoot up from cracks between each floor tile. In the second cycle phase of the fight, Heigan teleports himself up to the platform and will instantly kill those who tarry there. This means that the ranged and healing raiders have to join the melee group down on the poisoned floor, and the entire raid group has to do the zigzag manoeuvres across the room and back again to avoid the plague waves. This fight is aptly known to WoW inhabitants as the plague dance, based on the coordinated fashion the entire group has to move around the room to avoid the plague waves.

Originally, the ranged group was able to exploit an oversight in the room design for phase two, by moving off with the melee group to a tiny nook just to the right of the platform where the plague waves did not come out of the floor. Standing in a tiny tight-knit mass on a single floor tile, the ranged group would continue to safely mete out damage to Heigan on his platform while the melee simply stood in the nook and waited until they had to dance again upon Heigan's return to the floor. This strategy to downing Heigan was the way I knew the fight, and it gave me the huge advantage of being stationary in both phases. A mage is a caster class, meaning my mage has to stand stationary, for the most part, in order to be able to cast spells. At that point, her average cast time on her key damage spell was 2.4 seconds. Attempting to mete out damage on the move was extremely difficult for me, but the nook exploit allowed me to stand still and simply cast spell after spell, which maximizes my damage output. However, just after I joined Guild B and did my first few raids with them and after having downed Heigan with them (thereby proving my raiding worth) in the first week, Blizzard fixed the room's architectural 
oversight, rendering the nook unsafe for that strategy. Joining the guild raid group and heading into the room in the second week, I was unaware of the change. I was caught unprepared and uninformed. I promptly died in the second phase. Amid heckles of displeasure on Ventrilo voice chat from my guildmates and while waiting to be resurrected by a healer, I quickly searched the Internet for information on the change and on the new strategy for downing. I discovered I was to do the dance with everyone else, and that accepted strategy was to keep the damage-dealing to the first phase only for the ranged classes and simply do the dance in the second phase.

Unbeknownst to me however, Guild B officers disagreed with this strategy. Based on emerging theorycrafting around the change posted on the Elitist Jerks (EJ) community forums, ${ }^{39}$ the guild council believed it was possible for the ranged classes to both dance and dps simultaneously in the second phase. With this in mind, they were determined to down Heigan in record time, establishing Guild B as one to be reckoned with in overall Naxxramas progression statistics.

Given that I was not an EJ member, I was unaware of this theorycrafting, whereas all of the other raid guildmates that night were EJ members. Consequently, when I was resurrected and returned to fighting duty, and when the fight cycled around to the second phase, I simply danced, where my fellow ranged players danced and dealt damage. While we did down Heigan that night, albeit not with me alive at the end, the fight did not finish as fast as the guild officers and leader expected. Once the raid was over and we had all collected our gear loot and logged out,

\footnotetext{
${ }^{39}$ ElitistJerks.com is a well-known Internet community of self-styled "uber gamers", or serious power gamers. They take the gameworld design, mechanics and possibilities seriously, engaging deeply in what is called theorycrafting, or running numerical modelling to determine the best way to gear and play any class in World of Warcraft. The forums of EJ are filled with statistical scenarios and detailed overviews of how to squeeze a few more DPS out of one's gameworld characters. The community refers to the deliberately constructed identity of these gamers, as both elitist snobs about the best way to gear and play, and as a group that cares more for the numbers and potentials than for social niceties and manners. The latter is seen in the way in which the members interact in the forums, openly criticizing and flaming others and deliberately deleting and censoring any posts that do not meet their ideas of perfection.
} 
they went over the fight logs and ran the numbers. There they discovered I had not dealt damage at all in the second dance phase after my resurrection and I had won the roll on a pair of cloth shoes. This combination of a lack of desired performance coupled with the taking of gear was an apparently egregious violation. I had not performed to their standards and yet I had been rewarded or "paid" for my performance. It was the determining factor to my mage's expulsion from Guild B.

What did this teach me about serious guilds? I learned that the guild chat is not there for sociality or assistance. I learned that I could not ask for help with anything, and was expected to be aware of any gameworld changes or adjustments and how they would affect me. I was expected to adjust my action style accordingly. Regardless of cost, my gear had to be as perfect as possible, and no matter how bad the healers or tanks might be on any given evening, if I did not maintain the level of DPS the guild felt was optimal for my class and role, I would lose my spot in the raid group and potentially in the guild. The overall lesson was that raiding is the raison d'etre of the gameworld, and raiding is serious labouring, not fun play. Raiding guilds like Guild B take it as seriously as one would their paid non-gameworld job, and the Guild B leadership expect everyone else in the guild to do the same, regardless of individual circumstance.

What about the hybrid guilds? In the WoW gameworld parlance, a hybrid guild is one that shares many of the characteristics of a hardcore guild, but allows for a certain amount of collegiality and sociality among the members. In the hybrid guild Taryas subsequently joined, which I will call Guild C, this manifested as a looser raid group setup and an active guild chat channel, where members constantly shared their recent accomplishments, either around the 
gameworld's achievement system, or by posting the details of the most recent loot they had acquired. Questions to one another about class talent builds, casting sequences or where to obtain the best loot were common in Guild C's chat, as were requests to join heroic instance groups or to get crafted gear from one another. Hybrid guilds are often considered to be feeder guilds, in that members get their first exposure to serious raiding in these guilds, by being trained to hold a specific spot in a consistent raid group and then being expected to show up for raids on a reasonably frequent basis, and then members would take that experience and use it as leverage to try to secure a spot within a hardcore guild like Guild B. Guild C differed from Guild B in that Taryas was expected to attend raids with her assigned raid group if possible, but if my "real life" situation precluded my ability to raid via Taryas on any given night or week, so long as Taryas had RSVPd "Not attending" to the raid leader's invitation to the raid in advance, her spot in the raid group was secure. ${ }^{40}$

Failure to make it in a hardcore guild can be devastating for some inhabitants who seek out that level of commitment in their gaming. This points to ways in which an inhabitant's desire to participate in the gameworld at a high level of performance is often at odds with the requirements (the coercions) put forth by the raiding guilds that could enable this experience. Gaming in an MMOG is never wholly un-coerced activity and my experiences in both Guild B and Guild C demonstrated this quite fully. At times, being part of these guilds and fulfilling the requirements they put forth made my participation felt closer to a paid job than a voluntary hobby. Given this, can it still be considered leisure?

\footnotetext{
${ }^{40}$ I should point out that this might have differed had I played a key star role in the guild group, such as the guild's main tank or main healer. As a DPS however, the hybrid guild saw me as interchangeable with any other DPS class, an attitude in stark difference to the highly rationalized and carefully constructed raid group from Guild B.
} 


\section{WoW and Governmentality}

What I am seeing here is agreeable obligation, an attitude and form of behaviour that Stebbins (2008) argues is very much part of leisure. It is part of leisure because such obligation accompanies positive attachment to an activity and because it is associated with pleasant memories and expectations. One could argue that agreeable obligation in leisure is not really felt as obligation since the actor wants to do the activity anyway. Still, my research in serious leisure and my experiences in the WoW gameworld suggests a far more complicated picture. My guild mates and I in Guild B knew we were supposed to be ready at the entrance to Naxxaramas every evening at 8:30 pm server time, and we would be expected to arrive ready to do our duty and act our class to the best of our ability, for as long as the raid leaders decided to run that night. We had to make these raids a priority in our daily lives. As a condition of our guild acceptance, we were required to show up. Painting the picture this way though obscures a critical fact: this participation was not obligatory in an oppressive sense, but was also voluntary.

It was a seemingly strange amalgam of coerced behaviour that was nevertheless engaged in voluntarily. Raiding was agreeable obligation, then, and the fact that the obligation to participate was understood and accepted by me and my fellow inhabitants speaks to the ways in which human behaviour generally is controlled and constrained by social forces. In the case of raiding, that control is exerted via the lure of the material rewards for participation and the siren song of the possible social status upgrade that can occur for a raider who has participated in the successful completion of a specific raid boss or overall instance. Comparing this to the larger neoliberal capitalist context, with its valuing of material consumer goods, status seeking behaviour and conquer or be conquered competitive mentality, I find strong associations and 
alignments. Yet, as noted earlier, it was true that, at times, my partner, friends and acquaintances objected to the way I prioritized other commitments, in order to make time for these nightly raids. But where is the problem? If what is happening in the gameworld of WoW is simply reflecting and reinforcing the western neoliberal values and orientations of life outside of WoW, should not the obligations of WoW be viewed as just as acceptable and laudable as those of others?

This is not a question this project can answer, but it is a question worth asking, for at stake here is an understanding of the ways in which digitality and leisure are implicated within regimes of control via knowledge production and dissemination. Foucault $(1995 ; 2005)$ argued that the idea of sex, of a soldier, or a mental patient, is not a natural or obvious given, but is instead "classificatory thought" (2005, p. 8). This knowledge understanding is shaped and threaded through a history of negotiations and contexts between humans, regions, political systems and morality games, and these shape the manifestation and practices of subjectivity. I argue that the same is the case with the WoW inhabitants. It seems to me that the disconnect in understandings between a gameworld inhabitant's view of their WoW participation as a fun, rewarding, social and potentially relaxing activity and the general view of that participation as dangerous and suspect comes from a misunderstanding of the assemblage that is gameworld participation. That misunderstanding operates both overtly and covertly, and is interpreted and assumed variably by both inhabitants and non-inhabitants. Certainly as I was immersing myself in WoW life, I felt empowered and enabled by a perceived plethora of choice and possibility. I could play for work, for the process of gathering data, but I could equally also play for fun, for escape, for the joy of exploration, the satisfaction of achievement, and the feeling of flow when 
my character's abilities were completely maximized by me and I came out on top in the damage statistics for an instance. Despite these positive correlations between fun and choice and the WoW gameworld, there were also other influences and factors at work that acted as constraints against the gameworld's affordances. These constraints are ultimately prioritized and moralized choices, which then naturalize over time so that they come to appear to be intrinsic to the gameworld itself.

The norms of the WoW society on the realm I was part of seemed to strive to ensure that each inhabitant stayed focus on the gear grind. That gear grind was structured according to a very strict division of labour, rationalized and theorized down to the smallest of ratios of difference to healing, tanking and damage dealing, then broadcast back into the WoW gameworld as the only way to be as a hunter, a mage, a tank, a crafter, etcetera. Thus, rather than being able to play out the skills of Taryas in the spell skill rotations within I had found joy and interest and some success, I found myself in level 80 raids being told to play her skills out in a very restricted and rather boring method, in order to maximize my DPS output. Crafting did not escape this either. While a plate wearing tank such as my friend M. might find it fun and interesting to be a tailor who crafted cloth items, it was considered to be the "wrong" craft for a tank. Tanks are supposed to be miners and armorsmiths or weaponsmith, or perhaps jewelcrafters. Their crafting therefore was supposed to fit the overall package of their class and role, regardless of whether it fit the desires and interests of the inhabitant themselves. In this sense, both the gear grind and the crafting system was intended to serve a single purple - fit and kit an inhabitant down to a specific class/craft/role mould, so that the person could insert themselves into any raid or dungeon group and achieve the actual purpose of that group: get 
better stuff. Contrary to the myth of self determination and the liberal enjoyment of free time, the WoW mindset and activities that I encountered were not geared toward the inhabitants' own choosing and desiring, but were instead structured and dictated to the inhabitant along the same neoliberal governmentality as the rest of the western lifestyle outside of WoW.

Life within WoW is much like life outside of WoW. There is the overt stated set of possibilities for the world, which act as their allure and promise. There is a wide range of choice of play styles and experiences that the gameworld presents, within which I found a wide array of possibilities for class talent arrangement, gear choice and gear enhancement, character performance and the pursuit of the gameworld's experiences. At the same time, there are a number of constraints, built overtly into WoW's technology and technicity and manifested both overtly and covertly in the expectations of other inhabitants on the right talents for a hunter or mage, the best way to gear and enhance those classes, the proper way to queue up skills for maximum performance and the appropriate instances to conquer that matched the level of the character and the gear the character had. There is a strong theme of constraint embodied by WoW inhabitants, which goes against the popular and common theme of infinite choice and possibility within digitality. The strain of governmentality that I find imposed in WoW by inhabitants dictates a pursuit of only three or four ways to inhabit and play out a hunter or mage, rather than the seemingly infinite array of possibility. This limited choice is based on a deeply neoliberal ethos of individual peak performance and maximum efficiency, and has few to zero affordances for fun, for individual play styles, and for alternative perspectives.

\section{WoW Consumerism as Neoliberal Being}


Limitations and constraints that follow along neoliberal lines also manifest in the inhabitants' consumerist preoccupation with the act of pursuing, choosing, obtaining and enhancing gear, a practice that is called 'gearing', over the act of experiencing the gameworld's content as an end in itself. Indeed, rather than content being the raison d'être of WoW for its inhabitants, the end game state for most inhabitants is actually about gearing and the gear grind. While I may have involved myself in Guild B for research, at times it was difficult to not lose that objectivity and fall down the rabbit hole that is gearing, by getting immersed into that gearing mindset, rampant as it was among my fellow guildmates. It was insidious. By grouping up with fellow guildmates in order to 'grind up' up reputation, by constantly reading about gear choices on various meta-content websites or by the incessant demand for participation in instances to go after a specific piece of gear, the unspoken yet obvious gear grind by my fellow guildmates made it clear that gear, not content, reigned supreme within WoW. It may have been fun and interesting to down Heigan, but according to my guildmates approach to their WoW participation, the only right reason for killing him in a Naxxramas raid instance was to get those shoes for my mage. Downing Heigan for the thrill of it, or more simply to be able to experience Heigan's fight with me as a kind of gameworld content tourism was frowned upon and shut down by guildmates. The WoW message is clear: gearing trumps tourism.

This gear grind as neoliberal logic is a manifestation of what Stallabrass (1996) calls the numerical logic of games, ${ }^{41}$ as evidenced in that most common of neoliberal themes, progress. If neoliberal progress is a structuring principle of modernity, as Mitchell (2002) argues, and arises

\footnotetext{
${ }^{41}$ It should be noted that Stallabrass was theorizing before the rise and dominance of MMOGs, though his writing does suggest some awareness of the existence of MMOG's foundational ancestor form, the Multi-User Dungeon, or MUD.
} 
from a specific kind of rationality, then as this applies to WoW, Stallabrass is right in noting about digital games generally that "an idea of progress is always present in the game, shadowing and interpreting the action" (p. 90). Stallabrass says "there is a marked liberal and individualistic ethic behind such games, for the character develops through intrinsically unrewarding labour...[and] this growth is always a matter of trade" (p. 89). Within WoW, this logic is extended even further, for the WoW character, literally and figuratively, can only be developed through labour that is perceived by many to do little other than get gear; an occupation that is highly material and consumerist, infused deeply with ideas of progress and numerality, yet empty of freedom.

Taylor (2006) hints at this dichotomy between the idealized gameworld freedom and its actualized manifested ack of real freedom. She notes that there is always a perceived right way to play. There exists disconnects between game affordances and player policing of the apparently more desirable play methods. This 'right way' mashed up with the technical affordances and social governmentality are what creates the constraints of gameworlds. These social constraints actualize real constraints in gameworld participation and living.

Stallabrass notes that players not only adopt these constraints as necessary, but they naturalize them as a kind of immanent law of play, in which "the player not only identifies with the image but controls it in obedience to strict rules of conduct-or else!, and the sanction is usually a virtual death sentence-so conformity has been extended from assent to action" (1996, p. 89). Stallabrass speaks of ways in which the character progression in games echoes the capitalist logic of the exchange market and of investment capital: 
"The player's performance is of course expressed as a numbered score, while objects when captured or destroyed may become, at the moment of their extinction, a floating number, an economic element. Each element of the game, each virtual being or object, acts as a commodity, placed in an extensive metonymic chain in which each link is defined only in relation to the others" (Stallabrass, 1996, p. 90)

In this way, the numerical realism of game digitality is penetrated by the capitalist logic of monetary numerality. The neoliberal ethos of capitalist consumerism and the reducibility of everything to its component parts, be it human, machine, time or money is starkly apparent in gameworlds such as WoW. While Stallabrass' overall writing in this work displays a snobbish tendency for some apparent "real life" outside of games, he is nonetheless correct in singling out the numeric machine in games, opining "a tyranny of number is a founding principle of these games and to play successfully is to emulate the qualities of the machine" (p. 90).

This line of thinking that twins the machinic qualities of digitality to the engines of capitalism and numeracy and the neoliberal logics of modernity is one I find particularly compelling and interesting when examined within and around WoW life. If I take liberties with the machine notion and create a metaphor of capitalism from it, the machine is capitalist life itself, regardless of realm of existence. All of life today bears calculated and logical machinic qualities that are inserted into the larger machine that is capitalist modes of living. Given this, any displeasure towards gaming as a leisure activity vis-a-vis any other then appears curious. Whether this machinic mode is rendered visible in the stitched together monster that is Shelley's Frankenstein, in the insidious plastics of the Barbie Doll or in the smoothly rendered numerical polygons of the game avatar, the fictions with which individuals engage simply re-enact a story 
of each individual's now actualized cyborg being, which reinscribes a politics of everyday life that is rooted in hybridity (Haraway, 1991).

\section{Towards an Understanding of WoW}

Foucault (1995) has noted that our bodies were long ago broken down into their component parts: legs trained to march; hands trained to hold weapons and kill; arms trained to hold ploughs and sow grain; and heads and selves trained to view events in one way and not in another. Elias (2000) made similar note of the ways in which bodily actions are reshaped into a calculated system of call and response manners, designed to keep the machine of social order functioning along optimal lines, reducing violence and augmenting a kind of specified civility. From the moment pre-historic humans began to perceive a world that they felt they could make better through the use of some sort of tool, a natural or unconstructed mode of human living ceased to be possible. Given the ways in which human existence is utterly inseparable from technology use, there is no nature or natural state of being left to access, available for our return to it. Latour argues this crucial latter point:

We are not witnessing the emergence of questions about nature in political debates, but the progressive transformation of all matters of fact into disputed states of affairs, which nothing can limit any longer to the natural world alone - which nothing, precisely, can naturalize any longer. (2004, p. 25; original emphasis)

Latour's point? There is no Nature or natural to be found or lived any longer, but at one point in the past, Nature once was a matter of fact. It had clear boundaries, a definite essence and recognized properties (Latour, p. 22). Natural objects were part of the system that is Nature; birthed in the world, made of its raw materials, imbued with an essence that is finite and both 
graspable yet mysterious. The objects that we humans perceive today, both man-made and apparently natural, are never able to be those of Nature, and thus, as Latour has noted, understanding life is now a political concern. To build an understanding of what a human or what a life is, the examiner is no longer simply looking at and listing 'matters of fact', but rather is analyzing and describing shifting and disputed 'states of affairs'. There is no natural human available to be catalogued, having long ago been dissolved into logics of calculation, improvement and extension. While it is has become a truism to say that no part of any realm of the world has remained untouched by human hands and minds, this truism highlights an important aspect of the human experience-all of human nature is manufactured (Latour, 2004). To be human is to be machine. Human existence, human being, is machinic being. All debates about what a human is, or what human existence is, or what human activity is or should be, are not attempts to grasp matters of fact, but are instead political actions that work to try to bring into being a specific understanding and mode of hybrid existence (Haraway, 1999).

Each debate, then, about gaming or digital existence subtly or explicitly engages in political fabrications of 'matters of concern' over what a human has become or is becoming. When I hear talk of what gaming is as an activity, when I engage in the discussions on the oddities of game life or argue against the falseness of digitality, what I am inserting myself into is not a clear-cut discussion of the facts of alteration of a natural human into an unnatural realm. Rather, it would seem to me that I am inserting myself into political and moral debates on what realms of human existence are more desirable than others, and what mode of machinic existence is more palatable to humanity. 
What I see cropping up here is an issue of boundaries. With the boundaries between the natural and the technological eroded to a point of being near-invisible in non-digital life, the anxieties around digitality are simply old anxieties reconstructed and ported into a realm that seems different yet remains remarkably consistent with the historical human past. The boundaries between the digital and the non-digital appear more obvious. Does it require a computer to do? Or a cellphone? If so, it is a digital thing. If not, it is a 'real world' thing. While I have done work elsewhere on the boundaries issues between the apparent real and the contested digital $(2005,2006)$, and thus rehashing that divide here is unnecessary, what is germane to this work is the fact that there is still, four years later, a constant privileging for the actions and outcomes that apparently happen only in the non- digital realm.

\section{Contested Ontologies}

In my conversations with non-gameworld friends and family about gaming as an activity that I enjoy and as a world in which I enjoy spending time and socializing, or if I mention the sense of accomplishment I get when I finish a quest, gain a level or win a piece of gear in a raid, the joy and satisfaction I feel seems to get erased by their understanding of gaming as a weird thing to do. Over and over, the majority of reactions I have encountered can be grouped into either a dismissive stance (it is not a real world so it does not matter) or an alarmist stance (oh no! Do not become one of those). The dismissive stance is rather straightforward. The people I have met who have adopted this stance either see gaming as play, akin to something a child does, and dismiss my game 'play' as being inconsequential, or they see my gameworld participation as not 'truly' real, or as 'fake', and they dismiss it as unimportant. Against this rather 
straightforward reaction, the alarmist stance is more nuanced and possibly less reflexive on the part of those who demonstrate it. In the alarmist stance, I have heard stories of video game addiction, coupled with stories of job loss, divorce, credit card theft and other associated ills. The themes of the conversation noted earlier herein with J persist throughout other conversations I have had since I started participating in WoW. $\mathrm{J}$ has not been alone in telling me that playing WoW two hours a day counts as addiction and I should get help. Indeed, the addiction theme was one I encountered often. The alarmist stance seems most closely influenced by media reports (Some examples: Beaumont, 2009; Bell. 2009; Benedetti, 2007; Kennedy, 2008; Matthews; 2007; Modine, 2009; Richford, 2007; Smith, 2008; Shea, 2008; Tanner, 2007). While people I have spoken with do not usually remember where they heard the story they are citing to me, ("oh, on the news" is the closest most get to being able to say who told them or how they know) news media reports are the influence I heard cited the most.

The conversations with gameworld friends and other non-gameworld people I know who also participate in gameworlds is where things get really sticky. They replace these positive aspects with an anxiety over what I am becoming and how closely I am risking being that asocial sinister hacker-gamer figure, or the twitchy anti-social neurotically addictive counter-figure, and thus do they port over their anxieties about machinic existence into my voiced expressions of digitality. The specificity of my experience is thereby annihilated via the looming folk devil that is more real to them than the individual I am manifesting. Their understandings of my gaming experiences has appeared to delete their hearing of my satisfaction and acceptance of my digitality and replaced it with the fear of the machinic that is manifesting in all of us. 
Taylor (2006) calls for a return to realism in the study of games, away from the forced exoticism that characterized earlier game studies. She says of the 'fantastical' older approaches to studying games, gamers and game worlds, that such approaches:

may prevent a more nuanced understanding of player's relationships with these games as a kind of everyday technology. Our relationships with technological objects are always moving closer to the mundane... [and as such] we integrate systems into our everyday lives and, in turn, into our everyday social networks and practices...To imagine we can segregate these things - game and nongame, social and game, on- and offline, virtual and real—not only misunderstands our relationship with technology, but our relationship with culture. (pp. 152-153)

In speaking of the false dichotomies of the game/not-game debate (and in taking on Castronova's (2008) rosy prophecy-laden take on gaming), Taylor says, "MMOGs are particularly good at simultaneously tapping into what is typically formulated as game/notgame, social/instrumental, real/virtual. And this mix is exactly what is evocative and hooks many people" (p. 153). Extending this argument, I would say that this mix is also what seems to make people uneasy if they are not gameworld inhabitants. Gameworlds are slippery, tough to pin down and box into a conceptual frame. Are they play? They can be. But they are not just play, nor are they purely fun. "Using terms like 'fun', for example, may not help us to understand the diverse pleasures some players find in very instrumental or work-like play" says Taylor (p. 156). Beatty \& Torbert (2003) note that what feels like play on one day can easily shift and morph into feeling like work the next. 
I argue that this is exactly what happens in WoW. In fact, I suspect that a closer consideration and examination of the way many players perform their gameworld participation would bear more hallmarks of traditional notions of labour than that of leisure. Inhabitants rarely consider their participation to be inconsequential. ${ }^{42}$ It is certainly rarely completely uncoerced, as shown in every guild I participated within. In short, as demonstrated herein, WoW participation is time that is calculated, purposive, tracked, remunerated and consistently re-occurring. Thus, it runs contrary to Stebbins (2008) idea of leisure. Given the highly rationalized nature of WoW life, and the ways in which it closely reflects the neoliberal values of capitalism, rationality, materiality and self-actualization, WoW life is more closely aligned to a pursuit of labour than to a pursuit of leisure. The fact that WoW life skews this way, complete with the way every activity in the gameworld comes with remuneration, in both gold and gear, underlines this association between labour and WoW, and between neoliberal capitalism and WoW.

However, the gold I have made in the WoW economy cannot be used to pay my townhouse's rent, or buy my groceries or foot the bill for my bookclub's pub tab. Are they real? This is the issue. From what I have seen and experienced, the argument trump card in many noninhabitant's deck is that what happens in the gameworld is not 'real'. In this sense, reality is twinned to corporeality and to a kind of tangibility apparently perceived as grounded in paper money, face-to-face sociality and the more thorny question of the what someone is supposed to do with their leisure time.

\footnotetext{
42 This is so despite the repeated utterances in the gameworld's chat channel that WoW isn't "real life" and so "doesn't matter". These utterances are usually intended to provoke a reaction out of people, a large portion for whom WoW is real life and does matter.
} 
After all, when that raid group of nine of my guildmates and I are in Naxxaramas, fighting Heigan, none of us are fighting a Heigan that threatens to kill our biological flesh. The poison he tries to kill us with is not a biological weapon. The dances we do together as friends and guildmates in a raid group to avoid Heigan's attempts to kill us are not done in biological copresence. The death I experience in the game when I mis-step in the dance is not a biological death. The Saltarello Shoes I loot off of Heigan's corpse cannot be donned the next evening with a nice pair of jeans and worn out to a club for an evening of dancing with friends. Nor can we invite Heigan out to the club to dance with us.

But how and why does the digitality of the experience make the experience and the person any less valid or fulfilling within their digitality? I do not have a good answer to this, but I sense that this is an important question to ask. This is perhaps the crux of the matter to those who do not participate in MMOGs. Because all of that activity, all of that gameworld interaction and accomplishment and stuff matters to those who live in the gameworld part of their time. Yet to those who do not, that inability to make gameworld currency and gear translate into bioworld stuff, that absence of bioreality and lack of co-presence seems to be a big part of what makes the whole WoW life thing unreal and therefore inconsequential, or just plain irrational. The time spent in the company of these digital friends, in pursuit then of these digital goods, appears to onlookers and non-inhabitants as freakish and strange and outside of that which is normal for the life of an adult. As I recorded in my notes one evening after a bookstore shift, one of my coworkers remarked that being in WoW is a "stupid way to spend a Friday night" because it's all just "fake". But how is WoW's digitality ontologically any different from the pursuit of sociality and consumer goods in the non-WoW world at large? 
The contested reality of gameworlds and the activity that happens within them are the key sticking point in any argument towards naturalizing gameworld participation as a valid leisure activity. Taylor (2006) rightly notes that "our relationships with technological objects are always moving closer to the mundane" (pp. 152-153). This feels and seems right to me, but then, it probably should, as I have become an active participant in the technological environment that is WoW, along with being a trained observer more generally. The boundaries between the binaries Taylor mentions and that Beatty \& Torbert problematize are increasingly blurred or even vanished for me, over time, within WoW. However, to the non-participants and untrained observers, this erosion of the boundaries and discrediting of the binaries is not so obvious, nor is it desirable. As I experienced over and over again, this deliberate segregation and policing of the binary boundaries is exactly what tends to happen in the everyday non-gameworld context. There is a disconnect between the way WoW inhabitants, of which I now count myself as one, see the fluidity of life outside and inside the gameworld, and the way non-inhabitants view it.

The issue then is both ontological and cultural, grounded in the deeply materialist stance that comes from a neoliberal ethos. As lived by me and as I found corroborated throughout the conversations ${ }^{43}$ on the web and elsewhere, the clash is material. "We see MMOG players engaging in the game worlds they inhabit" Taylor writes (p. 154), which is not ontologically different than the way WoW inhabitants engage in role worlds outside of games, be it in the family home, the workplace, the shopping mall or the range of other communities open to any

\footnotetext{
${ }^{43}$ For one particularly notable example of such a conversation, see Appendix II.
} 
individual. The only apparent differences then are those of ontology, as seen in the category clashes, sociality misunderstandings, materiality disconnects, and currency nostalgia.

If the neoliberal values of free market dominance, currency valuation and freedom to express individuality are considered and evaluated against my gameworld experiences and observations, I see positive and negative associations. There is definitely a positive association between capitalism and commodification as a neoliberal value and the preoccupation with gear and gold among both Guild B and Guild C members. I frequently heard various guildmembers bragging about how much gold they had made by understanding the market dynamics of the WoW auction house system. Having the individual ability to gain wealth by manipulating the auction house flows and fluxes was a big part of personal stature within these guilds. So too was the ability to be "all in purples". This refers to the colour designation of the various gear tiers within WoW. Starting with gray items, understood to be "vendor trash" or only good enough to be sold to a vendor, and progressing along a colour scale through white (common), green uncommon), blue (rare) and then purple (epic), ${ }^{44}$ gear is the one of the main important commodities within WoW. This gear consciousness can be positively associated to currency valuation as well, in that gear functions within the game as a commodity. Through the various ways that gear is sought after, acquired, maintained then broken down for resale in another form, there is a currency valuation at work within the associations inhabitants have with their gear. ${ }^{45}$

\footnotetext{
${ }^{44}$ In the interests of completeness it should be noted that there is technically one more level of gear above purple: the orange or legendary level. However, this level is usually found on items that drop within specific instances and are able to be used only within that instance. As such, it is an all-but-invisible gear level to the average inhabitant, and is generally considered irrelevant to gear considerations.

${ }^{45}$ In a recent patch to the Wrath of the Lich King expansion, gear began showing its vendor sale value. Thus, Taryas' Saltarello Shoes are worth 5 gold, 62 silver, and 5 copper if sold to an NPC vendor. Of course, if disenchanted down to an abyss crystal and sold at the auction house, the transmuted form of those shoe can fetch a much higher price on that open market.
} 
The ethos of individuality is a more tricky positive association to find within the gameworld. While I often observed people expressing and espousing variations on the neoliberal attitude of "be all that you can be", my experiences in hardcore guilds certainly belie that attitude. Or, to be more precise, in those guilds, it became more a case of "be all that you can be, according to an elitist definition of what is best". Even that though, when analyzed, does not vary much from the actuality of non-gameworld life and living however. If I set aside an idealist view of the ethos, and if I acknowledge the ways in which elitist attitudes shape the possibilities for individuality, personal expression and being more generally, regardless of the realm of existence, then the gameworld sense of individuality closely associates to that of the non-gameworld sense.

Perhaps then the largest misunderstanding I find in what goes on in the gameworld is that mistaken muddling up of play and work, leisure and labour, that occurs both within gameworlds such as WoW and in the non-gameworld more generally. The difference that is the ontological category clash emerges from the fact that environments like WoW are mistakenly labelled games, by their creators and their inhabitants. This label erroneously lumps the act of participating in these MMOGs as being ontologically the same act as that of a child's play. It would seem that the everyday non-academic understanding of a game is that of a series of structured activities that act as a mild diversion, a light and deliberate time waster, possibly shared with friends, and intended to be 'fun'. In this sense, a game is a distraction that functions either as a pleasant way of deliberately 'wasting time', or as an avoidance technique, a way of distracting one's self from what is otherwise going on in life. Games are playful, easy to do, and completely free of life consequences. In many understandings, games are the quintessential 
activity of leisure. They are not immersive. They are not real spaces for existence and identity. Games are expected to be casual, inconsequential and short-lived.

The WoW gameworld and the life of the WoW inhabitant does not align to this commonsense game notion. The WoW inhabitants' digitality is immersive, requiring deep investments of time, labour and self. As I have discussed already, participation is often less about fun or play and more about getting 'stuff', improving one's digital self to demonstrate a kind of mastery and attaining a certain social status that comes from the twinning of the stuff and the mastery. Given this, I argue that the WoW gameworld is less of a game in the commonly understood sense of that term and more of a living and learning environment, ${ }^{46}$ a place in which to figure things out, to be something and become someone. As Consalvo (2007, p. 4) succinctly points out, "games aren't designed, marketed or played in a cultural vacuum". The fact that WoW is a living and learning environment that aligns to the neoliberal capitalist ethos seems less strange then when it is understood as an environment in which to be something and someone and not as a game to play. MMOGs like WoW are a medium far more than they are an activity. Yet the prevailing understanding of MMOGs vanishes this distinction. In this sense, an ontological misunderstanding is committed when activities in WoW are called gaming and the WoW environment itself is elided down and equalized out to a game. WoW is immersive, it is social, and to its inhabitants, it is deeply consequential and often is more work than play, more obligation than whim. In actuality, the mistake then is not to label WoW a game. Rather, it is to

\footnotetext{
${ }^{46}$ Analysing the full difference between the everyday sense of what a game is and the academic view of the role of games in learning life and values is outside the scope of this paper. For a good overview of how videogame environments are learning grounds for life, see Gee (2003).
} 
label WoW a game the way we understand of them in a neoliberal world, as something unimportant and separate and somehow less real than everyday normal living.

Unlike an equivalent online game, The Sims, which mimics and simulates everyday living, life in WoW is perversely fantastical, yet the context of life and being within WoW is identical to life outside of WoW. If both digitality and bio-existence are a kind of living, then calling WoW a game is a problem of mis-categorization, and this encourages inaccurate and misleading boundary maintenance. For those outside of the gameworld, there is little understanding of what happens in the gameworld during those hours of immersive participation. What concepts do crystallize, via media representations in particular, tend to be hackneyed. These concepts focus more on porting over the folk devil of the hacker, addict or misfit than they do on the actual gameworld environment, or social structure. ${ }^{47}$ As Taylor notes:

While much of what we hear about gaming in the popular press evokes images of alienation and isolation, it is often a grave misunderstanding of (or sometimes a willful bias against) the nature of these games. The sociality of the space is not simply a matter of players talking to each other but a web of networks and relationships-sometimes weaving on- and offline life, in-game and out-game-developing, and disintegrating, over time (Taylor, pp. 30-31).

The last two ontological errors I see in the way the WoW gameworld is generally understood manifest in and around WoW's materiality and its economy. Obviously, the world of WoW is a digital one, created in alphanumeric code sequences, brought to life via microchips

\footnotetext{
${ }^{47}$ See Fritz (2009) for one of the rare "big media" reports on WoW that reflected a reasonably accurate peek at the positive social side of the gameworld.
} 
and storage gigabytes and manifested via electronic pulses of light on liquid crystal displays. But the invocation of WoW as simply the results of its code and sequences and pulses is an inaccurate view of the materiality of the gameworld. Even if I set aside the stories of people selling gameworld items for non-gameworld national dollars, the gameworld is still heavily material, in and outside of its boundaries. The computers it runs on, via Blizzard's vast server farms, and via each inhabitant's machine and the entire assemblage is linked together in a vast technological array of critically material things. The biological actors who are enmeshed in that sociotechnical universe are but one part then of the materiality of the gameworld. The arguments I heard from people about the lack of reality that is gameworld participation, based as they were on the seeming immateriality of WoW, are false. When juxtaposed to the intensely material technologies, people and technicities that bring the WoW gameworld into being at every instant of every day, these arguments become absurd.

This is also true of the economy of the WoW gameworld, both within its own materiality and in its circulating sense more generally. Castronova (2003, p. 23) claims, "Game time is a substitute for other consumption goods, and it is also a substitute for work time". I am not so sure that WoW game time is a substitute for anything specifically, other than perhaps my own desire to shop in bricks and mortar retails stores, because I am able to satisfy that same persistent neoliberal urge to shop via shopping and buying in WoW's auction house, trade chat channel and by window shopping gear on the various metaworld WoW websites. It seems more likely to me that the economy of WoW is simply an extension of the kind of economy its inhabitants would like to have in their non-gameworld life: inhabitant controlled and managed via a technological 
system that makes quantifying, trading and equipping easy and hassle free, within a world in which currency is freely acquired through the course of the ebbs and flows of daily life.

Returning to the question of digital materiality, writers in the fields of Internet studies have begun calling for a re-shaping of old notions of materiality. Hayles observes that "virtuality is the cultural perception that material objects are interpenetrated by information patterns" (2001, p. 69) and she notes that the duality between the material and the 'virtual' first cropped up post World War II, in debates around information and nature. While I dislike the term virtuality, I find the definition and context most interesting. In order to free up capital to circulate widely (one of the chief early aims of neoliberal financial strategies), capital had to become dematerialized. It had to be transformed from matter (paper and metal, with physical transference from bank to hand) into information; transposed into bytes of data that could be streamed across the world via telephone lines and later IP networks.

A quick look around the North American world today, with its debit cards and electronic banking, and online shopping, and that early project is shown to be a smashing success. Common to life is the experience of paying for an experience (e.g. a movie, plane trip, a WoW subscription) without ever touching money as a material object in exchange for something that is more emotional information than object. If the idea of money as information rather than as material thing or object is understood and accepted, and if the idea of paying for experiences that leave little if any material traces is okay, then is it such a stretch to extend this argument out to the intensification of money as a thing that is no longer in and of itself material, but rather is increasingly simply information circulated via technological networks as currency for experiences that are also based solely on electronic? The question appears strange, at first, until it 
is extended to the logical and actual end point of that intensification, where not only is the money rendered as information alone, with no physical referent, but so too are the goods and services that it buys. The gameworld of WoW is material in its foundation and operation, but in its circulation and actualization, it is naught but experience. All the financial capital that circulates within and around the gameworld, to pay for the WoW subscription fees, to buy the gameworld goods or to pay the raid repair bill, all of it is streams of information alone, regardless of whether that currency is labelled Canadian or US dollars, or WoW gold.

I will leave this portion of the argument alone here, for it starts extending into semiotic meanings of symbols and referents. ${ }^{48}$ Nevertheless, my point is made: The capital that circulates in and around WoW and that shapes the digitality of WoW participation personifies the intensification and perfection of the kind of capital that neoliberal policies and approaches strive to achieve.

Despite the apparent conditions of possibility that digitality presents within WoW, I find it interesting that players nevertheless choose to perpetuate the same divisions of labour within the games role and class structures, crafting systems, and economies of finances and social capital as the ones they live in daily outside of WoW. Yes, the gameworld shuts down certain possibilities, such as being able to be a tank while playing a hunter, or doing high damage in melee as a hunter, but there is nothing inherent to the technicity of the gameworld that says that the point to the game's digitality is the gear grind and the pursuit of social capital as demonstrated by one's gear. Similarly, there is nothing structurally or technically limiting about

\footnotetext{
${ }^{48}$ For a much better take on the semiotic impacts of this issue, I would suggest reading Hayles (2001) and the stellar chapter 2 in Hayles' (1999) book, How we Became Posthuman.
} 
being at the maximum character level in WoW, which at the time of this writing was level 80 . In fact, it is quite the opposite - being level 80 means an inhabitant can solo many dungeons, travel anywhere in the vast world of Azeroth, work on a long list of possible achievements, craft anything if they have the profession for it, and generally pursue any kind of activity that they find interesting, rewarding or pleasurable. Yet from what I have lived and observed within WoW, it is generally understood that being 80 means doing raids and grinding for gear, period. I have found far more freedom to be whatever I wanted to be when Taryelle was level 30 than I have since she became level 80 . While it is not completely unusual to see dance parties spring up in the middle of Stormwind, or watch healing duels take place between two healer inhabitants, these and other activities are considered to be frivolous and against the real ethos of being 80 . Being 80 means being 'uber', having the best gear, downing the hardest bosses and generally demonstrating via gear and dungeon accomplishments that one's character is 'leet'. The inhabitants self-police and self-constrain the possibilities of the gameworld back down to the same old social relations of neoliberal capitalism, with its division of labour, flows of capital and the attendant perception and pursuit of status and power via roles and commodities that exists in the general world around the game, outside of its digitality.

The capitalist brilliance at work here is that life in WoW is as much about a hybridity of leisure and labour than life outside of WoW. WoW's digitality and the apparent freedom it presents is structured and shaped by the same neoliberal concepts of the flow of capital and the same divisions of labour that are found outside of the gameworld. Given the intensity and methods by which the inhabitants pursue gold and goods, then what does it say about the capital system within the game and circuits of capital more generally that not only do the WoW 
inhabitants do this all willingly, they also pay the Blizzard capitalists for the privilege of existing within that system?

It seems a corroboration of the paradox Adorno remarks on around hobbies and occupations. WoW seems to suit the idea that Adorno puts forth about the human condition. It is indeed strange and sad that even in WoW digitality, "the human condition which sees itself as the opposite of reification, the oasis of unmediated life within a completely mediated total system, has itself been reified just like the rigid distinction between labour and free time" (Adorno, 2002, p. 189). Rather than the leisure time of inhabitants being structured by discovery, self-determination and the joys of flaneurie, all of which are the myths of what WoW life is as sold by the Blizzard marketers, ${ }^{49}$ the actual fact of life of WoW is that it is just as much about the pursuit of money, power and status via consumer goods as life outside of WoW. "In capitalism, people are constantly frustrated with their inability to autonomously and freely direct their activities", argues Gunster (2004, p. 55), yet when WoW inhabitants embrace the digitality of WoW, they bring into the gameworld the same old attitudes and feelings of constraint from modern life and perpetuate and reproduce their conditions of frustration within the gameworld all over again.

\section{The Flows of Capital}

\footnotetext{
${ }^{49}$ The Blizzard sales pitch (2010) for the gameworld speaks of the vast possibilities apparently present within WoW: "Explore jagged, snowy peaks; vast mountain fortresses; and harsh, winding canyons. Witness zeppelins flying over smoldering battlefields; battle in epic sieges -- a host of legendary experiences await." According to Blizzard's own beginner guide (2009): "Unlike other MMORPGs, World of Warcraft allows players to play the game at their own pace, whether it be a few hours here and there or entire weeks at a time.... The quest system also provides an enormous variety of captivating quests with story elements, dynamic events, and flexible reward systems."
} 
While it is outside of the scope of this thesis to lay out a full overview of the flows of WoW capital, to understand those flows of capital and the commodities within WoW, I need only look to the crafting system to find an exemplar. The intent of the crafting system was surely meant as a way to provide an income for the inhabitants. Yet, in a system where the Saltarello Shoes are the best you can get for a given point in your gameworld life, what incentive is there for you to use the inferior crafted ones? According to the way capital flows in WoW, none. More often than not, the things that I crafted as a leatherworker or an alchemist got sold back to an NPC vendor for far less than the cost it required of me to make them. For other trades, like tailoring, the items they made were not as valuable as the pieces that went into making them, and so often those items got broken down into a kind of crystallized form (dust, essence or shard) and used to reinforce and enhance a piece of gear, or the crystal forms were sold off at the auction house to try to recoup the cost of what went into making that crafted piece.

So where is the attraction in crafting? Crafting within WoW seems to be encased in a strange structure of beliefs and materiality. On one hand, there exists a belief that what one crafts is potentially useful and is indicative of one's overall level of skill in the gameworld, yet this is generally belied by the structure of capital flows within the gameworld. There is a prevailing belief that the items and objects and consumables that are crafted by the gameworld's inhabitants will provide the crafter with a steady stream of capital, via the sale of the crafted goods to other inhabitants through the Auction House market or the city trade system. What I found in actuality, via my own crafting and observing the results of that of others is that much of what is crafted is considered to be only worthy to be vendored to an NPC vendor for a paltry few coins. 
It is true that there is social capital to be found in proclaiming and proving that I am a max-level leatherworker, because the achievement of the maximum skill level of my leatherworking craft-skill displays a seriousness and investment in the gameworld. However, very little social capital can be derived from the items I am able to craft, and there is little to no monetary capital in the resulting items themselves. The materials that go into the crafted item are intrinsically worth more as materials than they are as a crafted whole. The reality of crafting in a gameworld like WoW is that the capital investment in the crafting process is rarely realized at the end as a profitable endeavour between networks of human inhabitants. Instead, the investment is widely considered to be a 'gold sink', meaning it is simply a way for the socioeconomic structures of the gameworld to literally siphon off gold from the player-character inhabitants and put it back into the hands of NPCs. Crafting in WoW is not intended to produce capital, but rather to consume it.

Rather than finding others who were admiring of my crafting accomplishments in leatherworking, enchanting and alchemy, I was most often met with words of commiseration over the cost and effort of levelling those crafts, and the general inability to turn a profit from them. Frequently, in the city trade channels, I noticed conversations that proclaimed one person or another crazy for trying to level up a certain craft, with jewelcrafting most often singled out as the worst of the bunch. Thus, the only currency or social capital then that crafting seems to provide to the WoW inhabitants is that of a kind of suspect social status. It is suspect because it does often provide the inhabitants with a source of respect from others, but I encountered that respect twinned to an undercurrent of disbelief and pity. 
Crafting within WoW thus functions as a corroboration of the way the economy and labour work within WoW to perpetuate the ontological errors of common understandings of leisure and labour, and it shores up the myths of capitalism and neoliberal being more generally. Crafting within WoW sustains the capitalist paradox that is seen outside of WoW. Despite the neoliberal rhetoric that the open market within the gameworld will provide the means to individual success, freedom and actualization, and the idea that crafting within WoW is one of the inhabitants' gameworld hobbies, the truly successful pursuit and attainment of financial and consumerist capital both in and outside of the gameworld is dominated globally by those with an inordinate amount of labour power and an iron-clad control over the means and modes of production..$^{50}$

\section{WoW Living in Action}

So what is the activity that occurs in the WoW gameworld? Are the inhabitants engaging in leisure? Through the course of this thesis, in the research and reading and in being part of the WoW gameworld, I have been part of activities that are both leisure and labour. The WoW world takes work, dedication and commitment in order to be a full inhabitant and quite often felt more like work than play, even when removing the research aspect from my involvement. I have discovered that WoW is more than a game, and the activities I engaged in within that world were more than simple play or distraction or socialising. Between levelling three different types of

\footnotetext{
${ }^{50}$ Ironically, within WoW, this domination tends to be the purview of the 'gold farmers', businesses set up outside of WoW for the express purpose of farming materials and gear to sell to WoW inhabitants for both WoW gold and 'real world' currency. Despite the attempts by Blizzard to outlaw the practices of gold farmers, many gold farmer companies make their homes in countries where the cost of labour is trivial, human rights regarding labour conditions are minimal and trademark infringement and other business laws are difficult to police and prosecute. This seems a strong corroboration of the globalization thesis that is at the heart of the neoliberalism fable and the myth of capitalist possibility.
} 
crafting, selling crafted and dropped things on the auction house and being part of a guild swap system, I was integrated into an economic system.

I recognize that my involvement reflects who and what I am and why I entered WoW originally. With my approach being social-observational, both for this thesis and in life generally, I suppose it should not surprise me that I made strong connections and forged relationships with a whole variety of people that I met in the gameworld. I spent a great deal of time reading a lot of websites, blogs and chat forums, with the goal of learning as much as I could about the way the WoW gameworld worked, in everything from what was the best Hunter shot rotation to use for maximum DPS, to where to go to get the best gear to debates on why the arena PVP system seems broken with the introduction of the Death Knight class. Given my scholarly stance, this seems almost expected, in hindsight. I am surprised nonetheless at how invested I got in putting that knowledge into practice when questing, raiding or talking to guildmates. It became important to me not just to know all of that 'stuff', but also to use it, to share it, to build on it.

Given this, I think that the more interesting question to ask now is not the question of whether or not there is a negative stance towards online gaming, per my original research question. My involvement in WoW has answered that question in the affirmative for me, with little gray area. Nor is it that interesting now to me to answer if my gaming was leisure. Because of the ways I have problematized the notions of leisure and labour here when understood in the North American neoliberal context, it appears now that the idea of leisure as any realm outside of a purported realm of being called 'labour' or 'occupation' or 'career' is impossible. Equally impossible is the notion of separating out work and play within WoW. As I have demonstrated 
and discussed, the digitality of WoW is both leisure and labour, both work and play. That forced and false dichotomy between leisure and labour, a hobby and an occupation, now appears old and tired out to me. It has no place, certainly not in light of what I have lived these last months in and out of the WoW gameworld. The idea of digital leisure as being open to anything and full of possibility now also feels like another of the false siren songs of neoliberalism, making it yet more strange then the fact that its digitality is viewed with suspicion by many. Looking back on my own WoW digitality, and thinking through it in the ways I have done here already, I find myself agreeing uncomfortably with Adorno who says:

the reason why people can actually do so little with their free time is that the truncation of the imagination deprives them of the faculty which made the state of freedom possible in the first place. People have been refused freedom, and its value belittled, for such a long time that now people no longer like it (2002, p. 193).

I saw this in WoW and lived it there. Despite conditions of possibility within a new realm of being, and despite the freedom to find pleasure and self-determination within a whole range of activities, the digitality of WoW is reduced back down to the same tired modes of neoliberal being that are part of life outside of WoW.

There is an interesting reshaped question for me to ask now, and to consider examining and analysing in the future. If, as I have demonstrated, in the conditions of WoW digitality, with its flows of financial and cultural capital, and its modes of living, makes the WoW gameworld an excellent mirror and training ground for the entrenchment of neoliberal values and capitalism, 
then why is the time spent in the WoW gameworld viewed as suspect? This is a question I leave open for now.

\section{Conclusion}

We need the power of modern critical theories of how meaning and bodies get made, not in order to deny meaning and bodies, but in order to live in meanings and bodies that have a chance for a future.

Donna Haraway, (1999, p. 290)

I noted at the beginning that I would construct a story of ontological politics at work. I have told the story here of my own becoming an inhabitant in WoW, and I have discussed the reactions to and understandings of my gameworld digitality. Through my experiences and observations, I have articulated how participation in an MMOG such as WoW questions the belief of freedom within leisure generally and gameworld digitality specifically, and I have demonstrated how any attempts to police the artificial ontological boundaries between leisure and labour breaks down in the face of the actuality of WoW life. WoW digitality is simultaneously and variably labour and leisure, action and reaction, sociality and being. Within the realm of human living that it presents, the WoW gameworld provides an indoctrination field into the ethos of capitalist power relations, with its modes and means of production. Because of the way the inhabitants setup their own understandings of what one is supposed to do and be within WoW, I have argued that WoW acts as a full corroboration of neoliberal values and ethics. Yet gameworlds are not understood to be this, or do this.

New media technologies are becoming less visible, more diffused and socially normalized at a metaphorical level, because they are no longer novel or unusual. Thus, in the wake of the dot.com crash and a wave of accountancy scandals and bankruptcies, discourses about new media technologies in the press no longer simply pump out uncritical utopian and 
deterministic interpretations, in which society is metaphorically and primarily linked with the impacts of technology. A more balanced discourse is emerging, in which new media technologies are seen as ambivalent and problematic. Yet this is not true of gameworld participation. Outside of the business section of the local and national newspapers, MMOG participation in the popular press is still most often spoken of in dystopian terms. ${ }^{51}$ When they do appear, MMOGs such as World of Warcraft are usually spoken of as a nemesis or folk devil. They are the cause of addictions, and likened to illegal drugs such as cocaine, as is seen in the popular referral (e.g. Beaumont, 2009; Gonzalez, ND; Modine, 2009) to the derogatory pseudonym for WoW, "World of Warcrack".

What is more interesting to me is the fact that gameworld inhabitants themselves are put in a position where they must set up their own performance as gameworld inhabitants in opposition to this negative ontological stance. Be it in gaming magazines like PC Gamer, in the forums of game community websites like the popular Allakhazam.com, or in chat in or out of the gameworld, inhabitants stay on the defensive about their gameworld activity and friendships. Their stance is taken in contrast or solidarity to the gamer stereotype. As detailed and queried here, gameworld participation as a leisure activity is a beleaguered activity.

So in this sense, as I experienced it in my own life and saw it in the lives of others, as I heard it from friends who sometimes live in gameworlds and friends who do not, those of us who are game inhabitants continually construct our understanding of our participation in gameworlds

\footnotetext{
${ }^{51}$ Castronova's (2008) newest book is the lone wolf crying out in a utopian fashion for games. He argues that all of life will now need to feel as if it is fun play, the way it is in gameworlds. Companies that fail to produce that same sense of fun and commitment will die. Whether he is right or not remains to be seen, but his book certainly reads like a utopian handbook on the seeming wonderfulness of game life.
} 
around, through and against the larger diffused understanding of online gaming as a marginalized and suspect activity. WoW seems to function as a kind of training ground and reinforcement for the dominant values of the society in which it is embedded. Given the ways I have detailed how WoW participation mirrors the overarching neoliberal values and ethos of western society, accompanied by a decided governmentality, this dominant and prevailing notion of MMOG participation as suspect is odd and the reasons behind it deserve further study.

This performance of online gaming as a contested activity seems to make this notion into a mediator. Mediators are "continuous transformations of networks and assemblages: they transform rather than transport meaning" (Jensen, 2008). Gameworld participation and the generalized understandings of it as a potential leisure activity is read through the transient and uncertain meaning of what it is to be a human today, of what reality is, of what time and currency, leisure and labour all are. All of these ontological uncertainties shape and constrain the understandings of gameworld participation, and in the process continuously transform the act of gameworld participation for inhabitants. When immersed in the WoW gameworld, its activities and rewards, affordances and constraints seem natural, acceptable, and desirable to inhabitantactors. However, when carried beyond the boundaries of the gameworld, the assemblage network that is gameworld participation transforms and becomes a different set of actions, meanings and understandings, positioned against fluctuating and circulating ontologies as evidenced in nongameworld actors. In this sense, the online gameworld participant is not so much an actualized individual, nor is online gaming an actualized activity. Rather, it is a mediated assemblage of polarized interpretations and understandings that belie specific contested notions of possibility and desirability of being human in an increasingly digitized neoliberal world. 


\section{Appendix I - Glossary}

\begin{tabular}{|c|c|}
\hline MMOG & Massively multiplayer online gameworld \\
\hline $\log$ & \begin{tabular}{|l|} 
Login; enter the world (or re-enter) \\
\end{tabular} \\
\hline Grind & $\begin{array}{l}\text { To do the same action or task repeatedly in a game, usually for the } \\
\text { purposes of gaining experience, (XP), faction reputation or craft } \\
\text { materials }\end{array}$ \\
\hline PUG & $\begin{array}{l}\text { Pickup group (as opposed to a guild run); a group comprised of strangers } \\
\text { and intended to accomplish specific quest or dungeon goals }\end{array}$ \\
\hline NPC & Non player character \\
\hline Toon & Character controlled by an individual \\
\hline A main & $\begin{array}{l}\text { An individual's original and main character; often considered by the } \\
\text { individual as their primary and most important }\end{array}$ \\
\hline An alt & $\begin{array}{l}\text { Alternative character; a character played as a break or subordinate } \\
\text { character to one's main }\end{array}$ \\
\hline Class & $\begin{array}{l}\text { A class is a type of character, which in MMOGs is often roughly aligned } \\
\text { along three axes or meta styles: either healing (repairing players' } \\
\text { damage), tanking (holding monsters' attention and taking on their } \\
\text { damage) or damage (known colloquially as DPS). The healer is } \\
\text { inherently played at a distance (ranged), the tank is played up close by } \\
\text { necessity (within melee range) and the DPS are divided between ranged } \\
\text { and melee. Part of the class package is whether or not the character } \\
\text { wields magic, does physical damage, controls minions or pets, or is able } \\
\text { to heal themselves or others. }\end{array}$ \\
\hline DPS & $\begin{array}{l}\text { Damage per second; used in vernacular as either a type of player class or } \\
\text { as an action (e.g. "Looking for a dps for Naxx" versus "We DPSd him } \\
\text { down hardcore") }\end{array}$ \\
\hline Tank & $\begin{array}{l}\text { The plate-wearing character that soaks up the enemy's damage and } \\
\text { protects the group; Also (interestingly) called a meat shield }\end{array}$ \\
\hline Healer & $\begin{array}{l}\text { The cloth-wearing character that heals the damage received via a series } \\
\text { of spells and skillsets }\end{array}$ \\
\hline PvP & Player versus player \\
\hline PvE & Player versus environment \\
\hline$\overline{\text { BC }}$ & Burning Crusades expansion to WoW \\
\hline WoTLK & Wrath of the Lich King expansion to WoW \\
\hline
\end{tabular}




\begin{tabular}{|c|l|}
\hline Guild & $\begin{array}{l}\text { A group of loosely-connected individuals who share a common guild } \\
\text { identity; the requirements of the guild will vary depending on the } \\
\text { members, from social, to raiding with many gradients in-between. }\end{array}$ \\
\hline XP & $\begin{array}{l}\text { Standard abbreviation for Experience Points; the numerical value } \\
\text { assigned to each successful quest or kill in the game; contributes to level } \\
\text { gain }\end{array}$ \\
\hline Instance & $\begin{array}{l}\text { Commonly known as a dungeon; a gated section of the gameworld that } \\
\text { presents content specifically/privately to your gaming group; various } \\
\text { instances can be for groups of 5, 10, 25 or 40 inhabitants }\end{array}$ \\
\hline Raid & $\begin{array}{l}\text { Dual purpose term, referring either to a group of 10, 25 or 40 people who } \\
\text { form to take on an instance; or referring to the act of working in a group } \\
\text { of this size to do something that requires this size group (e.g. "Let's raid } \\
\text { Wintersgrasp and get some honor" }\end{array}$ \\
\hline Gear & $\begin{array}{l}\text { The ensemble of armour clothing, weapons, jewellery, trinkets, and } \\
\text { enhancement items that a character dons to better equip themselves for } \\
\text { their role. Gear is most often considered to be an enhancer of a } \\
\text { character's statistics (stats), such as Intellect, Stamina, Agility etc. }\end{array}$ \\
\hline
\end{tabular}




\section{Appendix II - Existentialism and WoW}

What follows is a selection of comments from a forum conversation about WoW life, entitled Existentialism and WoW (WoW Ladies Journal, 2009).

- "the game means a lot to me, for social reasons but also because $i$ have a sense of accomplishment because of it. once in a while, though, i'll panic a bit. because it IS just pixels. it's all an illusion (not a trick!). not really an accomplishment, but an appearance of one. and it is only cultural currency for a small group of people (well, i guess 11 million people isn't that small of a percentage, but...). to the general population i am quite nerdy and overly concerned about a game. and when $i$ think about it from their perspective, it kind of makes me flail"

- "I used to feel bad about it especially when I lived at home and had to live with people who didn't understand the appeal at all. However I realized that their hobbies were not any better or more satisfying than mine. For example what does following a sports team really make you gain in life? You meet people who enjoy the same team or sport, you keep track of all kinds of names and stats that outside of the sports fan world - no one cares about. You talk in terms that a non-sports fan would never understand (just like WoW terms), you feel like part of a group (like us and guilds) and sports games are definitely used as social outlets just like WoW. Its pretty much the same thing to me. I can think of plenty of examples like this."

If you were heavily into reading classic novels you might join a book club and learn all the names of authors, characters and titles of books but outside of your little world of other classical book lovers no one would really care. If you told someone that you were going to go home and read for 4 hours a night to reach your goal of reading 100 books in 100 days is that any different than raiding to get an achievement? They are both leisure activities. You don't gain anything from either activity except for your own enjoyment and sense of accomplishment."

- WoW is my ultimate guilty pleasure. We all have to have one - right?

- In every day life, you very rarely feel the sense of accomplishment that you day from play WoW for say 3 hours. I'm not saying that this feeling doesn't exist in RL, it's just harder to come by. In game, you can achieve this by leveling, downing a boss, clearing a raid, getting epic loot, maxing out a profession, having a ton of alts, having a ton of money, having a ton of mounts/pets/insert object here. But in life, it's not so easy and the feeling isn't as big. I know it sounds kinda sad but I really like that I have an outlet that I can interact with that improves my days tenfold. 
And the other half of it is the social side. Because it's not like we sit in a dark closet with our computer and hide from society. Many people, if not all, have blossoming relationships with people all over the world, many relationships that make it into RL. I hate that that implys that these in game friendships aren't real because they are, possibly more real than the ones with people in person.

- I sometimes get the feeling that someone is going to judge me because of the amount of time I spend playing a game but because I have the ability to be a successful student, have a part time job, have a social life and play WoW, I feel that the people who might make your accomplishments and friendships feel trivial and intangible really need to grow up and look past the facade. 


\section{References}

Adorno, T. (2002). The culture industry. New York: Routledge.

Allen, C. (1996). What's wrong with the "Golden Rule"? Connundrums of conducting ethical research in cyberspace. The Information Society, 12 (2), 175-187.

Altheide, D. L. (1987). Reflections: Ethnographic content analysis. Qualitative Sociology, 10 (1), 65-77.

Anonymous. (n.d.). Existentialism and WoW. Retrieved September 04, 2009, from WOW Ladies Journal: http://community.livejournal.com/wow_ladies/11186762.html

Bakardjieva, M., \& Feenburg, A. (2000). Involving the virtual subject. Ethics and Information Technology , 2 (4), 233-240.

Bartle, R. A. (1996). Hearts, clubs. diamonds, spades: Players who suit MUDs. Journal of MUD Research, 1 (1).

Beatty, J. E., \& Torbert, W. R. (2003). The false duality of work and leisure. Journal of Management Inquiry, 12 (3), 239-252.

Beaumont, C. (2009, July 24). Addiction therapists signing up to World of Warcraft. Retrieved August 13, 2009, from http://www.telegraph.co.uk/technology/news/5899659/Addictiontherapists-signing-up-to-World-of-Warcraft.html

Bell, V. (2009, December 18). The Addiction Habit. Retrieved January 5, 2010, from Slate: http://www.slate.com/id/2239010/

Benedetti, W. (2007, April 20 ). Were videogames to blame for a massacre? Retrieved August 12, 2009, from MSNBC: http://www.msnbc.msn.com/id/18220228/ns/technology_and_science-games/ 
Berg, B. L. (2004). Qualitative research methods for the social sciences. Toronto: Pearson.

Bergstrom, K. (2009, 08). Adventuring together: Exploring romantic couples use of MMOs as part of their shared leisure time. Unpublished MA thesis . Calgary, AB: University of Calgary.

Blizzard Entertainment. (2010). Retrieved January 9, 2010, from World of Warcraft - Sign up for a free trial: http://us.blizzard.com/en-us/games/wow/

Blizzard Entertainment. (2009). Beginner's Guide. Retrieved 12 27, 2009, from http://www.worldofwarcraft.com/info/beginners/index.html

Blizzard Entertainment. (2008, 12 23). World of Warcraft subscribers base reaches 11.5 millon worldwide. Retrieved May 12, 2009, from Blizzard.com: http://www.blizzard.com/us/press/081121.html

Blumer, H. (1954). What is wrong with social theory. American Sociological Review , 19, 3-10.

Brown, W. (2006). Regulating aversion: Tolerance in the age of identity and empire. Princeton, NJ: Princeton University Press.

Bryce, J. (2001). The technological transformation of leisure. Social Science Computer Review, $19(1), 7-16$.

Burton, T. L., \& Jackson, E. L. Reviewing leisure studies: An organizing framework. In T. L. Burton, \& E. L. Jackson (Eds.), Leisure studies: Prospects for the twenty-first century. Calhoun, C. (1980). Community: Toward a viable conceptualization for comparative research. Social History, 5, 105-129.

Callon, M., \& Latour, B. (1981). Unscrewing the big Leviathan: How actors macro-structure reality and how sociologists help them do it. In K. Knorr-Cetina, \& A. Cicourel (Eds.), 
Advances in social theoryand methodology: Towards an integration of micro- and macro- sociologies (pp. 277-303). Boston: Routledge.

Castronova, E. (2008). Exodus to the virtual world: How online fun is changing reality. New York: Palgrave.

Castronova, E. (2003). On virtual economies. Game Studies , 3 (2).

Cavalli, E. (2008, 10 12). Game|Life. Retrieved May 12, 2009, from Wired.com: http://www.wired.com/gamelife/2008/10/qa-world-of-war/

Consalvo, M. (2007). Cheating: Gaining advantage in videogames. Cambridge, MA: MIT.

Crawford, G. (2005). Digital gaming, sport and gender. Leisure Studies , 24 (3), 259-270.

Critcher, C., \& Bramham, P. (2004). The devil still makes work. In J. T. Haworth, \& A. Veal (Eds.), Work and leisure (pp. 34-50). New York: Routledge.

Davies, C. A. (1999). Reflexive ethnography: A guide to researching self and others. New York: Routledge.

De Grazia, S. (1962). Of time, work and leisure. Garden City, NY: Anchor.

Dean, M. (1999). Governmentality: Power and rule in modern society. Thousand Oaks, CA: Sage.

Denzin, N. (2004). The art and politics of interpretation. In S. N. Hesse-Biber, \& P. Leavy (Eds.), Approaches to qualitative research (pp. 447-472). New York: Oxford University Press.

Denzin, N. (2009). The research act: A theoretical introduction to sociological methods. Edison, NJ: Transaction Publishers. 
Dolwick, J. (2009). The social and beyond: Introducing Actor-Network Theory. Journal of Maritime Archaeology , 4, 21-49.

Dumazedier, J. (1974). Towards a society of leisure. Amsterdam: Elsevier.

Elias, N. (2000). The civilizing process: Sociogenetic and psychogenetic investigations (2nd Edition ed.). Malden, MA: Blackwell.

Entertainment Software Association. (2009, June 2). 2009 sales, demographic and usage data: Essential Facts about the computer and video game industry. Retrieved August 21, 2009, from Entertainment Software Association: http://www.theesa.com/facts/pdfs/ESA_EF_2009.pdf

Ess, C. (2008, November 13). An impending global ICE age? Cybernetic pluralism in an emerging global information and computing ethics. Milwaukee, WI: Center for Information Policy Research. Retrieved from http://www4.uwm.edu/sois/cipr/docs/ess.pdf

Ess, Charles \& the AoIR Ethics Working Group. (2002, November 27). Ethics Guide. Retrieved February 13, 2009, from Association of Internet Researchers: http://www.aoir.org/reports/ethics.pdf

Featherstone, M. (1982). The body in consumer culture. Theory Culture Society, 1, 18-33. Feenburg, A., \& Bakardjieva, M. (2004). Virtual community: No killer implication. New Media \& Society, $6(1), 37-43$.

Fernback, F. (1999). There is a there there: Notes towards a definition of cybercommunity. In S. Jones (Ed.), Doing Internet research: Critical issues and methods for examining the net (pp. 203-220). Thousand Oaks, CA: Sage. 
Foucault, M. (1995). Discipline and punish: The birth of the prison. (A. Sheridan, Trans.) Toronto: Vintage.

Foucault, M. (2005). The birth of the clinic. New York: Routledge.

Frankel, M. S., \& Siang, S. (1999, November). Ethical and legal aspects of human subjects research on the Internet. Retrieved August 9, 2009, from American Association for the Advancement of Science: http://www.aaas.org/spp/sfrl/projects/intres/report.pdf

Frisby, D. (1989). Simmel and leisure. In C. Rojek (Ed.), Leisure for leisure: Critical essays (pp. 75-91). New York: Routledge.

Fritz, B. (2009, September 9). World of Warcraft's strong bonds. Los Angeles Times .

Gee, J. P. (2003). What video games have to teach us about learning and literacy. New York: Palgrave.

Gibbons, D. (1975). Unidentified research sites and fictitious names. American Sociologist, 10, $32-36$.

Gonzalez, L. (ND). When two tribes to go war: A history of video game controversy. Retrieved from Gamespot: http://www.gamespot.com/features/6090892/index.html

Gunster, S. (2004). Capitalizing on culture. Toronto: University of Toronto Press.

Haraway, D. (1991). Simians, Cyborgs and Women: The Reinvention of Nature. New York: Routledge.

Haraway, D. (1999). Situated knowledges: The science question in feminism. In A. Elliott (Ed.), The Blackwell reader contemporary social theory (pp. 287-299). London, Blackwell.

Hardball with Chris Matthews. (2007). Were games to blame? Retrieved January 9, 2010, from http://www.msnbc.msn.com/id/21134540/vp/18202630\#18202630 
Harvey, D. (2005). A brief history of neoliberalism. New York: Oxford University Press.

Hayles, N. K. (1999). How we became posthuman: Virtual bodies in cybernetics, literature and informatics. Chicago: University of Chicago Press.

Hayles, N. K. (2001). The condition of virtuality. In P. Lunenfeld (Ed.), The digital dialectic: New essays on new media (pp. 69-94). Cambridge, MA: MIT Press.

Hemingway, J. L. (1999). Critique and emancipation: Toward a critical theory of leisure. In E. L. Jackson, \& T. L. Burton (Eds.), Leisure studies: Prospects for the twenty-first century (pp. 487-505). State College, PA: Venture Publishing.

Herring, S. (1996). Linguistic and critical analysis of computer-mediated communication: Some ethical and scholarly considerations. The Information Society , 12 (2), 153-168.

Hunnicut, B. (1990). Leisure and play in Plato's teaching and philosophy of learning. Leisure Sciences , 12, 211-227.

Iso-Ahola, S. (1997). A psychological analysis of leisure and health. In Work, leisure and wellbeing (pp. 133-146). New York: Routledge.

Iso-Ahola, S. E., \& Mannell, R. C. (2004). Leisure and health. In J. T. Haworth, \& A. Veal (Eds.). New York: Routledge.

Iwaski, Y., \& Mannell, R. (2000). The effects of leisure beliefs and coping strategies on stresshealth relationships: A field study. Leisure/Loisir , 24, 3-57.

Jensen, S. S. (2008). Avatar-based sense makings and communication practices in the metaverse. Retrieved March 20, 2009, from Roskilde University digital archive: http://diggy.ruc.dk:8080/retrieve/12266 
Jones, G. (2002). Killing monsters: Why children need fantasy, super heroes, and make-believe violence. New York: Basic Books.

Kelly, J. R. (1999). Leisure and society: A dialectical analysis. In E. L. Jackson, \& T. L. Burton (Eds.), Leisure studies: Prospects for the twenty-first century (pp. 53-68). State College, PA: Venture Publishing.

Kelly, J. R. (1978). Situational and social factors in leisure decisions. Pacific Sociological Review, 21 (3), 313-330.

Kelly, J. R. (1974). Sociological perspectives and leisure research. Current Sociology , 22, 127158.

Kendall, G. (2003). From liberalism to neoliberalism. Queensland University of Technology. Brisbane: Paper presented to the Social Change in the 21st Century Conference.

Kennedy, H. (2003). Technobiography: Researching lives, online and off. Biography, 26(1), $120-139$.

Kennedy, P. (2008, June 8). Craft addicts: Do online games trigger a new psychiatric disorder? Retrieved February 05, 2009, from http://www.boston.com/bostonglobe/ideas/articles/2008/06/08/craft_addicts/

Kjolsrod, L. (2009). How innocent is our scientific vocabulary? Sociology , 43 (2), 371-387.

Latour, B. (2004). Politics of nature: How to bring sciences into democracy. Cambridge, MA: Harvard University Press.

Latour, B. (2005). Reassembling the social: An introduction to Actor-Network Theory. Cambridge, MA: MIT Press.

Latour, B. (1987). Science in Action. Cambridge, MA: Harvard University Press. 
Law, J. (2004). After method: Mess in social science research. Toronto: Routledge.

Law, J. (2003, December 6). Networks, relations, cyborgs: On the social study of technology. Retrieved August 28, 2009, from Centre for Science Studies: http://www.comp.lancs.ac.uk/sociology/papers/Law-Networks-Relations-Cyborgs.pdf Maanen, J. V. (2004). End to innocence: The ethnography of ethnography. In S. Nagy HesseBiber, \& P. Leavy (Eds.), Approaches to qualitative research (pp. 427-446). New York: Oxford University Press.

Mannell, R. C., \& Reid, D. G. (1999). Work and leisure. In E. L. Jackson, \& T. L. Burton (Eds.), Leisure studies: Prospects for the twenty-first century (pp. 151-165). State College, PA, Venture Publishers.

Marx, K. (2008). Capital. (D. McLellan, Ed.) New York: Oxford.

Marx, K. (2007). Economic and philosophic manuscripts of 1844. (M. Milligan, Trans.) Mineola, NY: Dover Publications.

Maslach, C., \& Goldberg, J. (1998). Prevention of burnout: New perspectives. Applied and Preventive Psychology, 7, 63-74.

Matzat, U. (2004). Cooperation and community on the Internet: Past issues and present perspectives for theoretical-empirical Internet research. Analyse \& Kritik, 26 (1), 63-90.

McArthur, V. (2008). Real ethics in a virtual world. CHI Proceedings - Works in progress (pp. 3315-3320). Florence: Association for Computing Machinery (ACM).

Mckee, H. A., \& Porter, J. E. (2009). Playing a good game: Ethical issues in resesarching MMOGs and virtual worlds. International Journal of Internet Research Ethics , 2 (1). 
Mitchell, T. (2002). Rule of experts: Egypt, techno-politics, modernity. Los Angeles: University of California Press.

Modine, A. (2009, February 27). World of Warcraft: The crack cocaine of the computer world. Retrieved August 12, 2009, from The Register: http://www.theregister.co.uk/2009/02/27/world_of_warcrack/

Mol, A. (1999). Ontological politics: A word and some questions. In J. Law, \& J. Hassard (Eds.), Actor network theory and after (Vol. 46, pp. 74-89). Malden, MA: Blackwell.

Moorehouse, H. (1989). Models of work, models of leisure. In C. Rojek (Ed.), Leisure for leisure: Critical essays (pp. 15-35). New York: Routledge.

Neumeyer, M., \& Neumeyer, E. (1958). Liesure and recreation. New York: Ronald Press.

Nissenbaum, H. (2004). Hackers and the contested ontology of cyberspace. New Media \& Society, 6(2), 195-217.

Ong, A. (2006). Neoliberalism as exception: Mutations in citizenship and sovereignty. Durham, NC: Duke University Press.

Paccagnella, L. (1997). Getting the seat of your pants dirty: Strategies for ethnographic research on virtual communities. Journal of Computer-Mediated Communication, 3 (1).

Paccagnella, L. (1997). Getting the seat of your pants dirty: Strategies for ethnographic research on virtual communities. Journal of Computer-Mediated Communications , 3 (1), 1-16.

Paradis, T. \&. (2006). Snapping digital reality. Trials \& Tribulations: Negotiating research methods. Montreal.

Paradis, T. (2005). Fear, risk in the digital anomaly. Association of Internet Researchers annual meeting. Chicago. 
Paradis, T. (2006). Managing digital fear \& risk. Canadian Sociology \& Anthropology Association annual meeting. Toronto.

Pieper, J. (1999). Leisure, the basis of culture. Indianapolis, IN: Liberty Fund.

Rethberg, J. W. (2008). Quests in World of Warcraft: Deferral and repetition. In J. R. H. G. Corneliussen (Ed.), Digital culture, play and identity. Cambridge, MA: MIT Press.

Richford, N. (2007, November 22). World of Warcraft addiction: Fact or fiction? Retrieved February 5, 2009, from Associated Content news: http://www.associatedcontent.com/article/456551/world_of_warcraft_addiction_fact_or.h tml?cat $=9$

Roberts, K. (1999). Leisure in contemporary society. London: Tavistock.

Robson, K., \& Robson, M. (1999). Your place or mine? Ethics, the researcher and the Internet. In T. Welland, \& L. Pugsley (Eds.), Ethical dilemmas in qualitative research.

Rojek, C. (1985). Capitalism and leisure theory. New York: Tavistock.

Rojek, C. (1983). Emancipation and demoralization: Contradicting approaches in the sociology of leisure. Leisure Studies , 1, 83-96.

Rojek, C. (1989). Leisure and the ruins of the bourgeois world. In C. Rojek (Ed.), Leisure for leisure: Critical Essays (pp. 92-113). New York: Routledge.

Rojek, C. (2004). Postmodern work and leisure. In J. T. Haworth, \& A. J. Veal (Eds.), Work and leisure (pp. 51-66). New York: Routledge.

Rojek, C. (1993). Ways of escape: Modern transformations in leisure and travel. Landham, MD: Rowman \& Littlefield Publishers. 
Rose, N. (1999). Powers of freedom: Reframing political thought. New York: Cambridge University Press.

Schwartz, H., \& Jacobs, J. (1979). Qualitative sociology: A method to the madness. New York: The Free Press.

Sharf, B. F. (1999). Beyond netiquette: The ethics of doing naturalistic discourse research on the Internet. In S. Jones (Ed.), Doing Internet reseasrch: Critical issues and methods for examining the net (pp. 243-256). Thousand Oaks, CA: Sage.

Shea, C. (2008, April 21). Confessions of a World of Warcraft Addict. Retrieved August 18, 2009, from http://pc.ign.com/articles/868/868083pl.html

Shibutani, T. (1966). Improvised news: A sociological study of rumour. New York: BobbsMerrill Company.

Shogan, D. (2002). Characterizing constraints of leisure: A Foucaultian analysis of leisure constraints. Leisure Studies , 21, 27-38.

Silverman, M. (2006, May). Beyond fun in games: The serious leisure of the power gamer. Unpublished thesis. Montreal: Concordia University.

Simon, B., Boudreau, K., \& Silverman, M. (2009). Two players: Biography and 'played sociality' in EverQuest. Retrieved June 7, 2009, from Game Studies: http://gamestudies.org/0901/articles/simon_boudreau_silverman

Smith, M. (2008, February 13). Wedding woes: The dark side of Warcraft. Retrieved August 15, 2009, from Yahoo Games:

http://us.il.yimg.com/videogames.yahoo.com/feature/wedding-woes-the-dark-side-ofwarcraft/1186366 
Stallabrass, J. (1996). Gargantua: Manufactured mass culture. New York: Verso.

Stebbins, R. A. (2005). Choice and experiential definitions of leisure. Leisure Sciences , 27, 349352.

Stebbins, R. A. (2008). Serious leisure. London: Transaction Publishers.

Stocking, G. W. (1985). Observers observed: Essays on ethnographic fieldwork. Madison, WI: University of Wisconsin Press.

Sudweeks, F., \& Rafaeli, S. (1996). How do you get a hundred strangers to agree? Computer mediated communication and collaboration. In T. M. Harrison, \& T. Stephen (Eds.), Computer networking and scholarship in the 21st century university (pp. 115-136). Albany, NY: SUNY Press.

Sutherland, W. C. (1957). A philosophy of leisure. Annals of the American Academy of Political and Social Science, 1-3.

Sylvester, C. (1999). The western idea of work and leisure: Traditions, transformations, and the future. In E. L. Jackson, \& T. L. Burton (Eds.), Leisure studies: Prospects for the twentyfirst century (pp. 17-33). State College, PA: Venture Publishing.

Tanner, L. (2007, June 22). Is video-game addiction a mental disorder? Retrieved August 12, 2009, from MSNBC: http://www.msnbc.msn.com/id/19354827/ns/technology_and_science-games/

Taylor, T. L. (2006). Play between worlds: Exploring online game culture. Cambridge, MA: MIT Press.

The Local. (2008, November 17). Swedish boy collapses after 20-hour World of Warcraft binge. (http://www.theregister.co.uk/2009/02/27/world_of_warcrack/). 
Thorne, B. (2004). "You still takin' notes?". In S. N. Hesse-Biber, \& P. Leavy (Eds.), Approaches to qualitative research (pp. 159-176). New York: Oxford University Press.

Turkle, S. (1995). Life on the screen: Identity in the age of the Internet. New York: Simon \& Shuster.

Turner, B. S. (1996). The body and society (2nd Edition ed.). New York: Sage.

Van Maanen, J. (2004). An end to innocence: An ethnography of ethnography. In S. N. HesseBiber, \& P. Leavy (Eds.), Approaches to qualitative resesarch (pp. 427-446). New York: Oxford University Press.

Veal, A. (2004). A brief history of work and its relationship to leisure. In J. T. Haworth, \& A. Veal (Eds.), Work and leisure (pp. 15-33). New York: Routledge.

Veal, A. (2001). Leisure, culture and lifestyle. Society and leisure, 24 (2), 359-376.

Wilensky, H. (1960). Work, careers and social integration. International Social Science Journal, $12(4), 543-560$. 